\title{
Neurotransmission in Mood Disorders
}

\author{
Zdeněk Fišar, Jana Hroudová and Jiř́ Raboch \\ Charles University in Prague and General University Hospital in Prague \\ Department of Psychiatry, First Faculty of Medicine, Prague \\ Czech Republic
}

\section{Introduction}

Mood disorders are characterized by depression, mania, or both. There are two groups of mood disorders, depressive disorders and bipolar disorder. Bipolar disorder is characterized by intermittent episodes of mania or hypomania and depressive episodes; rapid cycling, mixed states, and psychotic symptoms occur in some cases. Depression is a serious mental disorder that manifests with depressed mood, loss of interest or pleasure, feelings of guilt or low self-worth, disturbed sleep or appetite, low energy, and poor concentration. Mania is the opposite of depression; it is a state of abnormally elevated or irritable mood, arousal, and/or energy levels. Depression and mania are thought to be heterogeneous illnesses that can result from dysfunction of several neurotransmitter or metabolic systems.

The base of biological psychiatry is an assumption that human mind is connected with human body so that mental disorders (processes) are accompanied with biochemical changes, which can be measured. The second issue of biological psychiatry is a causality of all natural processes, including human mind. Molecular psychiatry studies disorders in human mind from the neurochemical, neurophysiological, neuroendocrine and genetic point of view mainly. It is postulated that mood disorders are caused by or associated with the disturbance of nervous signal transmission in the brain at the level of chemical synapses. On the molecular level, there is impaired neurotransmission mediated by neurotransmitters, their receptors and transporters, and by intracellular processes coupled to the activation of receptors for neurotransmitters and growth factors.

Because of difficult availability of human brain tissue for neurochemical measurements, psychotropic drugs effects are studied with the purpose to select those components of intracellular signalling pathways, which could be responsible for the therapeutic effects of tested drugs and consequently be related to origin of the disease. Results support the hypothesis that the treatment with antidepressants, mood stabilizers and even some antipsychotics leads to effects similar to neurotrophic and anti-inflammatory. Due to feedbacks inside the neuron the attention is devoted to pathways connected with receptors for monoamine neurotransmitters, receptors with inner calcium channel, and receptors for neurotrophins or Wnt glycoproteins. The role of neurochemical hypotheses of mood disorders is to suggest the relationship between symptoms of the disease, changes in signalling pathways and mechanisms of action of psychotropic drugs. 
Understanding of neurochemistry of mood disorders as well as molecular mechanisms of action of antidepressants and mood stabilizers are necessary to declare valid molecular theory of the disorder as basis of effective diagnosis, prevention and treatment. However, sensitive and specific genetic, biochemical, physiological, neuroendocrine or other biological tests have not been so far developed to be capable for diagnosis of mood disorders and their subtypes or for prediction of efficacy of current pharmacotherapy. It seems that leading role in neurochemistry of mood disorders could be awarded to disturbed monoamine neurotransmission, dysfunction in energy metabolism of neurons, modulation of inflammatory pathway, and changes in activities of transcription factors, neurotrophic factors and other components involved in neuroplasticity and apoptosis.

Basic findings about signalling pathways included both in pathophysiology of mood disorders and in mechanisms of action of administered psychotropic drugs are summarized in this chapter. Finally, there are summarized advances in neurochemical hypotheses of mood disorders.

\section{Synaptic signal transduction}

Synaptic signal transduction is complex process by which a neurotransmitter (extracellular signalling molecule) is released in response to action potential or other stimuli and activates a specific membrane receptor that leads to alteration of intracellular molecules forming a cellular response. Signal transduction system consists of many components (neurotransmitters, specific receptors, ion channels, G proteins, effector enzymes, transporters and other membrane proteins, second messengers, protein kinases, phosphatases, transcription factors, neurotrophic factors etc.) and numberless interactions, interconnections and feedbacks among them. Structure and composition of lipid bilayer also plays an important role, because of the fact that most of membrane proteins require interaction with specific phospholipids or with cholesterol for their optimal function. Signalling pathways included in the pathogenesis of mood disorders are primarily activated mostly by serotonin (5-hydroxytryptamine, 5-HT), norepinephrine, dopamine, glutamate and $\gamma$ - aminobutyric acid (GABA), i.e. they are connected with the processes in adenylate cyclase and phosphoinositide systems and with changes of intracellular ion concentrations, especially with calcium. Only selected components of signalling pathways are presented supposed to play a key role in pathophysiology and neurochemistry of mood disorders.

\subsection{Neurotransmitters}

A multitude of chemicals called neurotransmitters mediate intercellular communication in the nervous system. There are several groups of neurotransmitters: classical neurotransmitters, neuropeptides, endocannabinoids, nitric oxide (NO), and carbon monoxide (CO). Although they exhibit great diversity in many of their properties, most of them are stored in vesicles in nerve terminals (except for endocannabinoids, NO and CO) and are released to the extracellular space via processes requiring calcium ions. Their action is terminated by reuptake into presynaptic terminal or glia cells or by catabolism in extracellular space (e.g. in synaptic cleft) or in presynaptic terminal.

All classical neurotransmitters are synthesized in nerve terminals. The first molecule to be implicated as neurotransmitter was acetylcholine (ACh). ACh is synthesized from choline 
and acetyl-coenzyme A in the nerve endings; reaction is catalyzed by the enzyme choline acetyltransferase. ACh is rapidly degraded in synaptic cleft by the enzyme acetylcholinesterase.

There are three major amino acid neurotransmitters in the nervous system: GABA, glycine and glutamic acid. GABA and glycine are inhibitory neurotransmitters; glutamate and aspartate are excitatory neurotransmitters.

Monoamine neurotransmitters, such as dopamine, norepinephrine or serotonin are the most important neurotransmitters in pathophysiology of mood disorders and in mechanisms of action of antidepressants. Catecholamines (dopamine, norepinephrine and epinephrine) are synthesized from tyrosine. Dopamine is formed by tyrosine hydroxylase catalysed hydroxylation (rate limiting step) and decarboxylation of tyrosine. Norepinephrine is formed by hydroxylation of dopamine in presence of dopamine $\beta$-hydroxylase. Indolamines (serotonin and tryptamine) are synthesized from tryptophan by hydroxylation and decarboxylation; tryptophan hydroxylase mediated reaction is the rate-limiting step. Action both of catecholamines and indolamines on target cells is terminated much more slowly than that of acetylcholine; they are removed from synaptic cleft by reuptake. The major enzymes involved in the catabolism of catecholamines are monoamine oxidase (MAO) and catechol-O-methyltransferase (COMT). Serotonin is metabolized by MAO.

A great number of neuropeptides have been discovered and new neuropeptides being identified continually. All neuropeptides are synthesized in the cell body. The action of neuropeptides in the synaptic cleft is terminated by peptidases; there is no reuptake for neuropeptides. Neuropeptides usually act as co-transmitters and their transduction mechanism is coupled with $G$ proteins.

The endocannabinoids are a family of lipid neurotransmitters that mediate retrograde signal from postsynaptic neurons to presynaptic ones (Fišar, 2009). Nitric oxide and carbon monoxide have specific properties from among neurotransmitters, since the NO or CO does not interact with membrane receptors but diffuse to target intracellular receptor (Hill et al., 2010; Snyder \& Ferris, 2000). Abundant recent evidence favours a neurotransmitter/neuromodulator role for D-serine, because the $\mathrm{D}$-serine, rather than glycine, is the endogenous ligand for $N$-methyl-D-aspartate (NMDA) receptors in many brain structures. D-serine is synthesized mainly in glial cells and it is released upon activation of glutamate receptors (Oliet \& Mothet, 2009).

\subsection{Growth factors}

Growth factors are proteins that stimulate cellular growth, proliferation and differentiation, and promote cellular survival. They are essential for development and function of nervous system and have important function in neurotransmission. They are released from different cells; after interaction with membrane receptors changes in activity of intracellular enzymes occur leading to changes in gene expression and production of cellular molecules. Mechanism of their action is similar to action of neurotransmitters, but they are not released in response to membrane depolarization and to changes of intracellular calcium levels. Growth factors that promote the survival, development and function of neurons are known as neurotrophic factors. From the psychiatric point of view neurotrophins are the most important class of growth factors. 
Neurotrophic factors act by preventing the neuron from initiation of programmed cell death (apoptosis); they induce differentiation of progenitor cells to form neurons. The term "neurotrophin" is reserved for four structurally related neurotrophic factors: nerve growth factor (NGF), brain-derived neurotrophic factor (BDNF), neurotrophin-3 (NT-3), and neurotrophin-4 (NT-4). Each of four neurotrophins activates one or more of three trk (tropomyosin-related kinase) receptors with intracellular tyrosine kinase activity called trkA, trkB and trkC. Furthermore, each neurotrophin can still bind (with low affinity) to neurotrophic receptor p75 (p75NTR), homologous to tumour necrosis factor (TNF) and without any tyrosine kinase activity.

BDNF has a key role in stress response and in action of antidepressants. Exposure to stress has been shown to decrease the expression of BDNF. Series of studies support the hypothesis that a reduction of BDNF could contribute to depression and that antidepressants mediate their therapeutic benefits by increasing levels of this factor in the hippocampus (Castrén et al., 2007; Castrén \& Rantamäki, 2008; Duman \& Monteggia, 2006).

\subsection{Neurotransmitter receptors}

Receptor is macromolecule specialized on transmission of information. It is defined as binding site with functional relationships. Receptor complex includes: 1. Specific binding site; 2. Internal ion channel or transduction element; 3. Effector system (ion channel or system of second messengers). Activation of receptors with internal ion channel leads to rapid change in membrane potential and to prompt cellular response. Activation of receptors coupled with $G$ proteins leads to slower response through activation of effector system. Effector system includes $G$ protein activated ion channels or enzymes; $G$ protein activated enzymes generate second messengers, which activate protein kinases. Protein phosphorylation plays a significant role in a wide range of cellular processes. Transcription factors can be phosphorylated too, and phosphorylated transcription factors serve as third messengers, which activate gene expression.

Receptors are able to adapt their properties to increased or decreased activation. Changes in the density of receptors are known mechanism of their adaptation (receptor downregulation or up-regulation). Additionally, response to receptor activation can be altered at unchanged density of receptors, because regulation of properties of receptors may consist of decreased or increased activity of post receptor events (desensitization or hypersensitivity).

\subsection{Neurotransmitter transporters}

Neurotransmitter transporters are necessary for synaptic transmission just as receptors, ion channels, G proteins and effectors. Generally, neurotransmitters are removed from synaptic cleft by enzymatic degradation or by active transport to presynaptic button or to surrounding glia cells. There are three main classes of membrane transporters: 1 . Transporters dependent on sodium and chlorine transport serotonin, norepinephrine or dopamine back into presynaptic part; this enables that neurotransmitters may be stored in vesicles and repeatedly released in response to action potential; 2. Vesicular transporters carry neurotransmitters into synaptic vesicles; 3 . Sodium dependent transporters are localized in the membrane of glia cells and transport neurotransmitters such as GABA, glutamate or aspartate into glia cells. 
Functional polymorphisms in the promoter region of the serotonin transporter (SERT, 5HTT) gene and BDNF gene were found to moderate the influence of stressful life events on depression (Aguilera et al., 2009; Caspi et al., 2003).

\subsection{Postreceptor events}

It is assumed that signal transduction mediated by receptors associated with $G$ proteins and 2nd messenger systems are altered at mental disorders and during treatment with psychotropic drugs. After activation of receptor by first messenger $G$ proteins are activated and activated $G$ proteins activate effectors enzymes, such as adenylyl cyclase or phospholipase $\mathrm{C}$, and second messengers are produced. Second messenger activates protein kinase of type A, C or calmodulin (CaM) dependent, which catalyses phosphorylation of cellular proteins and physiological response to receptor activation arises. Second messengers generated by enzymes activated by $G$ proteins include cyclic adenosine monophosphate (cAMP), cyclic guanosine monophosphate (cGMP), inositol trisphosphate $\left(\mathrm{IP}_{3}\right)$, diacylglycerol (DAG), calcium $\left(\mathrm{Ca}^{2+}\right)$, metabolites of arachidonic acid and nitric oxide.

There are many neurotransmitters, many receptors, less G proteins and a few effector systems. However, there are many feedbacks at the cellular level and many cross-reactions at the intracellular level. Individual signalling systems interact together and form complex intracellular system, which enables neurons to compile signals from the different neurotransmitter systems, and which is involved in regulation of neuroplasticity and stress response. Reversible phosphorylation of proteins is probably the crucial molecular mechanism, which is used to realize the biological response to extracellular signals in target neurons. Attention is paid to cAMP dependent protein kinases (PKA), protein kinases C (PKC) activated by DAG, protein kinases dependent on calcium and calmodulin (CaMK), and protein kinases $\mathrm{B}(\mathrm{PKB}, \mathrm{Akt})$. Transcription factor $\mathrm{CREB}$, neurotrophin $\mathrm{BDNF}$, glycogen synthase kinase-3 (GSK-3) and components regulating programmed cell death, especially family of Bcl-2 proteins and various mitochondrial factors (including $\mathrm{MAO}$, enzymes of respiratory chain and mitochondrial DNA) are intensively studied, as well.

\subsubsection{Monoamine oxidase}

The enzyme monoamine oxidase (MAO; EC1.4.3.4) is a mitochondrial enzyme, which catalyzes oxidative deamination of biogenic and xenobiotic monoamines. It regulates the metabolic degradation of catecholamines and serotonin in neural and other target tissues. Major physiological role of intraneuronal $\mathrm{MAO}$ is to keep cytosolic monoamine concentrations very low. MAO exists in two isoforms that differ in substrate preference, inhibitor specificity, tissue and cell distribution, and immunological properties (Bach et al., 1988). The type A (MAO-A) metabolizes 5-HT and is sensitive to inhibition by low concentrations of clorgyline, whereas the type B (MAO-B) prefers benzylamine or 2phenylethylamine as substrates and is sensitive to inhibition by low concentrations of $l$ deprenyl. Tyramine, tryptamine, dopamine, norepinephrine and epinephrine are equally well oxidized by both isoforms of MAO (Youdim et al., 2006). The high levels of both forms are found in the brain; MAO-B is found in dopamine-secreting neurons in the brain.

MAOs have an important role in brain development and function, and MAO inhibitors have a range of potential therapeutic uses (Ramsay \& Gravestock, 2003). Generally, 
selective inhibitors of MAO-A and nonselective MAOIs seem to be effective in the treatment of patients with depression, panic disorder, and other anxiety disorders (Stahl \& Felker, 2008). It is supposed that MAO-B inhibition may slow the course of various neurodegenerative disorders; thus, selective inhibitors of MAO-B may be efficacious in treatment of Parkinson's disease (Horstink et al., 2006) and possibly of Alzheimer's disease (Riederer et al., 2004).

\subsubsection{Transcription factor CREB}

The allocation of information and memory to specific cells and synapses within a neural network is modulated by many synaptic, cellular, and intercellular components and by mechanisms working at different time scales (Silva et al., 2009). The transcription factor CREB (cyclic adenosine monophosphate response element binding) regulates transcription of many genes and has a well-known role in the learning related to synaptic plasticity (Carlezon et al., 2005). CREB is also involved in antidepressant response (Chen et al., 2001). Increase in CREB function can enhance memory; however, cognitive performance can be disrupted under some circumstances. CREB activity has sometimes beneficial, sometimes detrimental roles, depending on the brain region involved. Therefore, alterations in CREB function do not produce uniform effects throughout the brain (Blendy, 2006; Carlezon et al., 2005; Tardito et al., 2006).

\subsubsection{Bcl-2}

Bcl-2 (acronym for B-cell CLL/lymphoma 2) protein family is included in the regulation of apoptotic cell death and is formed from members with both antiapoptotic (e.g. Bcl-2, Bcl-xL, Bcl-w) and proapoptotic (e.g. Bax, BAD, Bak) activities. There are a number of theories concerning how members of the Bcl-2 family exert their effects. E.g., proteins from Bcl-2 family together with other factors control the permeability of mitochondrial membranes (Chipuk \& Green, 2008). The main changes in mitochondria during apoptosis are mitochondrial outer membrane permeabilization MOMP (regulated by members of Bcl-2 family) and depolarization of inner membrane. Bcl-2 itself is antiapoptotic; it reduces apoptosis by sequestration of caspases, by inhibition of release of mitochondrial apoptotic factors and by increasing of calcium uptake into the mitochondria. It is supposed that neurodegenerative diseases, including schizophrenia and mood disorders, may result from an abnormal ratio or function of pro- and antiapoptotic factors.

\subsubsection{Glycogen synthase kinase 3}

Glycogen synthase kinase 3 (GSK-3) is serine/threonine kinase that phosphorylates glycogen synthase and many other substrates such as transcription factors, enzymes and cytoskeletal elements. In human, it occurs in 2 isoforms, GSK-3a and GSK-3 $\beta$; biological functions of $\beta$ isoform have been more analyzed, it is widely present in the brain. Role of GSK-3 was found in different diseases, Alzheimer's disease, diabetes mellitus type 2, various carcinomas (Peineau et al., 2008), as well as in pathophysiology and treatment of bipolar disorder (Gould et al., 2007). Activity of GSK-3 is regulated by phosphorylation; phosphorylation on tyrosine residues increases the enzyme efficiency, phosphorylation of final serine has inhibitory effects. Furthermore, GSK-3 can be inactivated by stimuli coming 
from different signalling pathways, e.g. Wnt pathway (Fig. 5), phosphoinositide 3-kinase (PI3K) pathway, from PKA, PKC or from others. Main signalling pathways modulated by GSK-3 are insulin pathway, pathway of neurotrophic factors and Wnt pathway.

Different antidepressants, antipsychotics, amphetamines and growth factors have direct or indirect effects on GSK-3 and GSK-3 mediated signalling pathways. From the view of biological psychiatry, there is an important finding that GSK-3 is directly inhibited by lithium (by competition with $\mathrm{Mg}^{2+}$ ions) and indirectly inhibited with valproate; both of them are used in the treatment of bipolar disorder. GSK-3 inhibition is antiapoptotic, because of generally proapoptotic action of GSK-3. The hypothesis is tested that lithium (and other medications) can due to the GSK-3 inhibition induce cellular processes leading to changes in bioenergetics, neuroplasticity, neurogenesis, stability and survival of neurons (Gould \& Manji, 2005).

\section{Signalling pathways}

There is relatively small amount of signalling pathways initiated by activation of membrane receptors, which leads to the majority of important intracellular physiological processes. Their modulations influence gene expression and the function of cellular proteins, the change of synaptic functions, neuroplasticity and the response to neurotransmitters, neuropeptides, neurohormones, glucocorticoids and other bioactive molecules. Understanding of these signalling pathways is essential for insight to pathogenesis and pathophysiology of mood disorders (Fišar \& Hroudová, 2010).

\subsection{Adenylate cyclase pathway}

The mechanism of activation of the adenylate cyclase system is well known (Fig. 1). Neurotransmitter or other agonist binds to specific binding site of $G$ protein-coupled receptor (GPCR) and activates $G$ proteins. Main $G$ proteins, regulating activation of adenylate cyclase (also known as adenylyl cyclase, $A C$ ), are $G_{s}, G_{q}$ and $G_{i}$. Activated $G a_{s}$ or $\mathrm{Ga}_{\mathrm{q}}$ subunits bind to $\mathrm{AC}$ and activate it directly; free $\beta_{\gamma}$ complexes activate certain $\mathrm{AC}$ subtypes, as well. Activated AC catalyses conversion of ATP to cAMP; presence of $\mathrm{Mg}^{2+}$ ions is required and reaction is stopped by $G$ protein inactivation. $\mathrm{Ga}_{\mathrm{i}}$ subunits decrease intracellular cAMP levels by inhibition of AC. Indirectly, AC activity can be modulated through the activation of phosphoinositide system, when protein kinases $C$ (PKC) and calcineurin are activated. cAMP activates cAMP-dependent protein kinases (PKA). cAMP decomposition into $5^{\prime}$-AMP is catalyzed by phosphodiesterase (PDE) in the presence of $\mathrm{Mg}^{2+}$. Activated PKA phosphorylates neuronal proteins; it leads to cross-connections of various signalling pathways and to different physiological effects (Sands \& Palmer, 2008; Taylor et al., 2005). Phosphorylation (activation) of transcription factor CREB and consequent expression of neurotrophin BDNF seems to be important for therapeutic efficiency of antidepressants (Duman et al., 1997). Further, phosphorylation of nuclear factor $\mathrm{KB}(\mathrm{NFKB})$ is required for activation of transcription and interaction with CREB binding protein (CBP). NFKB obviously participates in survival of neurons (Hayden \& Ghosh, 2004). PKA supports the neuronal survival by inhibition of proapoptotic factor BAD and by activation of NFAT (nuclear factor of activated T cells) protein (Wu et al., 2007). Importance of APC (anaphase-promoting complex) inactivation is also studied in processes of axon growth, neuronal survival and synaptic functions (Kim \& Bonni, 2007). 


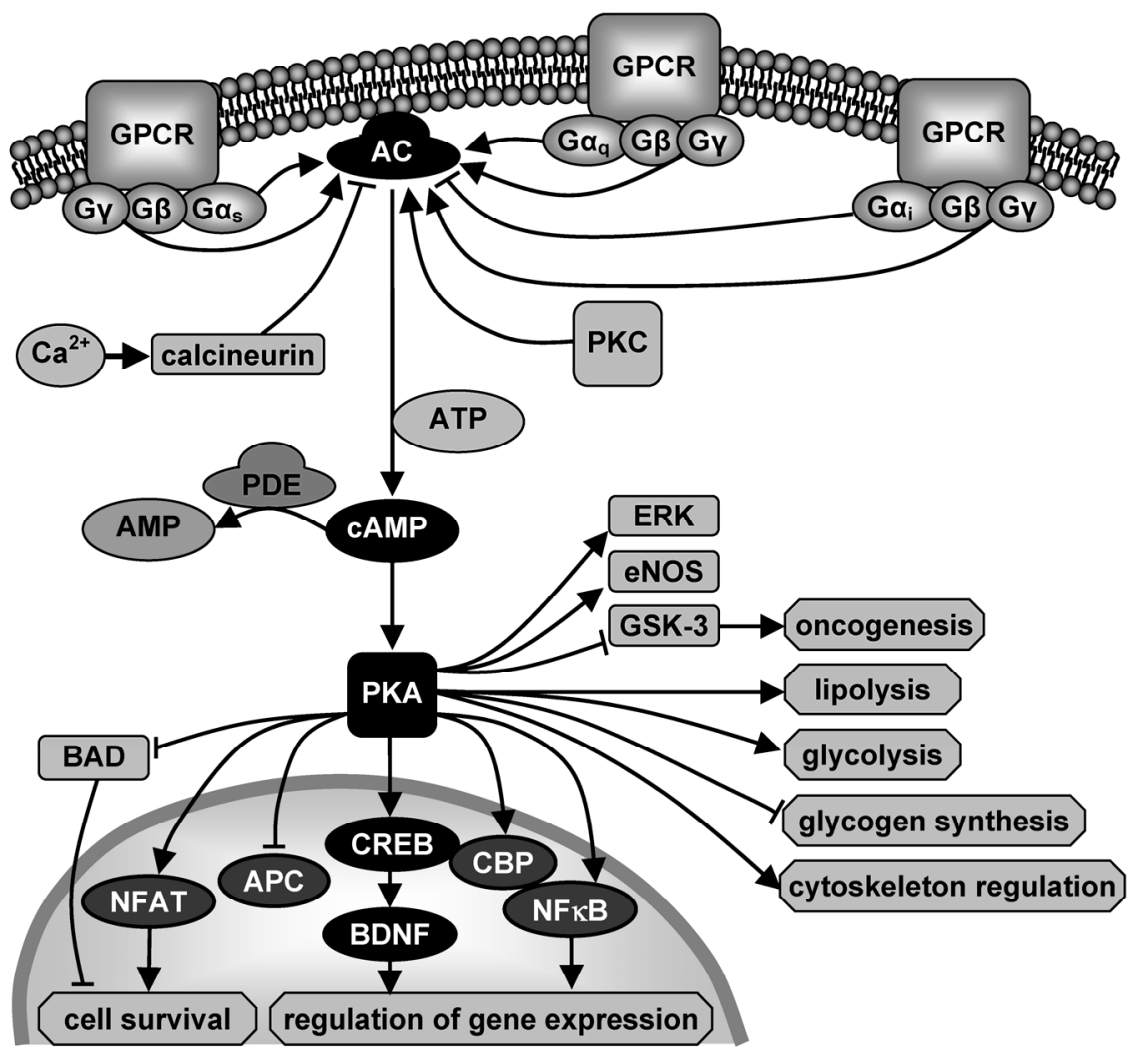

AC - adenylate cyclase (adenylyl cyclase); AMP - adenosine monophosphate; APC - anaphasepromoting complex; ATP - adenosine-5'-triphosphate; BAD - proapoptotic factor from Bcl-2 family (Bcl-2-associated death promoter); BDNF - brain-derived neurotrophic factor; cAMP - cyclic adenosine monophosphate; CBP - CREB binding protein; CREB protein - cAMP response element-binding protein; eNOS - endothelial nitric oxide synthase; ERK - extracellular signal-regulated kinase; GPCR G protein-coupled receptor; GSK-3 - glycogen synthase kinase-3; NFKB - nuclear factor $\mathrm{kB}$; NFAT nuclear factor of activated T cells; PDE - phosphodiesterase; PKA - protein kinase A, cAMP dependent protein kinase; $\mathrm{PKC}$ - protein kinase $\mathrm{C} ; \longrightarrow$ - activation; $\longrightarrow$ - inhibition

Fig. 1. Adenylate cyclase pathway (Fišar \& Hroudová, 2010). Detailed description in the text.

\subsection{Guanylate cyclase pathway}

Guanylate cyclase (GC, also known as guanylyl cyclase) catalyses production of cyclic guanosine monophosphate (cGMP) from guanosine triphosphate (GTP); presence of $\mathrm{Mg}^{2+}$ is required. There are two types of GCs, soluble (sGC) and membrane (Fig. 2). Membranebound form of GC is activated by peptide hormones; sGC is a receptor for nitric oxide (NO). The cGMP is a regulator of ion channels conductance, glycogenolysis and apoptosis; it also relaxes smooth muscles. cGMP degradation to $5^{\prime}$-GMP by phosphodiesterases (PDEs) is analogous to cAMP degradation. cGMP-dependent protein kinase (PKG) is activated by cGMP; PKG type I is expressed in specific brain regions. 


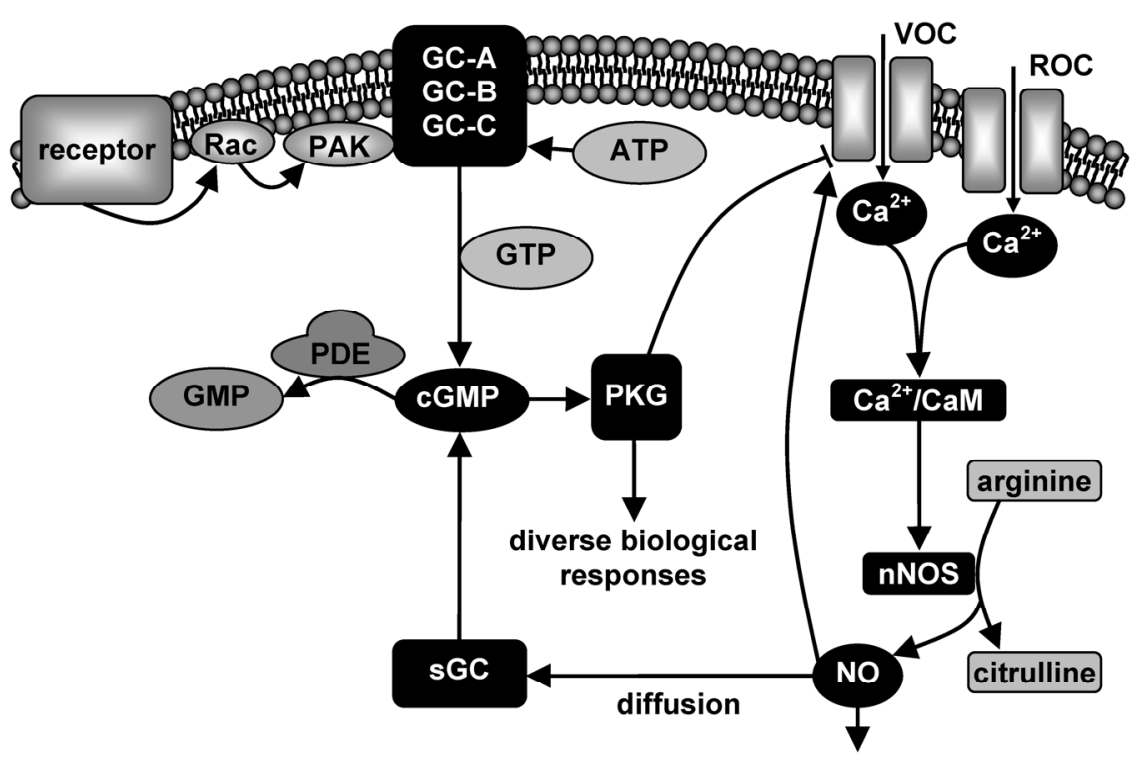

ATP - adenosine-5'-triphosphate; CaM - calmodulin; cGMP - cyclic guanosine monophosphate; GC guanylate cyclase (guanylyl cyclase); GTP - guanosine-5' -triphosphate; NO - nitric oxide; nNOS neuronal nitric oxide synthase; PAK - p21 activated kinase; PDE - phosphodiesterase; PKG - protein kinase G; Rac - small G protein with GTPase activity; ROC - receptor-operated channel; sGC - soluble guanylate cyclase; VOC - voltage-operated channel; $\longrightarrow$ - activation; $\longrightarrow$ - inhibition

Fig. 2. Guanylate cyclase pathway. Detailed description in the text.

\subsubsection{Membrane guanylate cyclase}

There are seven mammalian transmembrane GCs. GC-A and GC-B are natriuretic peptide receptors, GC-C can be activated by guanylin or uroguanylin (bacterial enterotoxins). The principal function of plasma membrane GCs in the CNS is modulation of sympathetic activity, inhibition of arginine vasopressin secretion, diminished salt appetite and water drinking, and effects on blood pressure/volume-regulating regions in the brain (Kuhn, 2003). Signalling pathway that provides a general mechanism for diverse signalling receptors to increase the cGMP concentrations was supposed in following sequence (Fig. 2): 1. Activation of membrane receptor, 2. Activation of Rac protein (small signalling G protein with GTPase activity) via guanine nucleotide-exchange factor, 3. Activation of p21 activated kinase (PAK) by Rac, 4. Activation of membrane GC by PAK, and 5. cGMP production (Guo et al., 2010).

\subsubsection{Soluble guanylate cyclase and nitric oxide}

In the brain, metastable free radical NO production is linked to the calcium $\left(\mathrm{Ca}^{2+}\right)$ influx during membrane depolarization through voltage-operated channels (VOC), e.g. L-type calcium channels, or after activation of receptor-operated channels (ROC), e.g. NMDA ionotropic glutamate receptors. Calmodulin (CaM) is activated following the increase of intracellular calcium and neuronal NO synthase (nNOS, NOS-1) is activated by $\mathrm{Ca}^{2+} / \mathrm{CaM}$; 
nNOS catalyze conversion of arginine to $\mathrm{NO}$ and citrulline. NO regulates many kinds of ion channels, including voltage-gated (Jian et al., 2007) and ligand-gated $\mathrm{Ca}^{2+}$-channels. NO functions as a neurotransmitter by diffusing through the membranes of postsynaptic cells, where it binds in sGC and activates this enzyme to convert GTP into the cGMP (Snyder \& Ferris, 2000). Thus, increased cGMP production could be attributed to NO, establishing a role for $\mathrm{NO}$ in mediating actions of glutamate in the brain. Two major signalling mechanisms, namely cGMP pathway and $S$-nitrosylation, mediate the cellular effects of NO. It has been reported that cGMP-mediated processes occurs at low NO concentrations, whereas $S$-nitrosylation occurs when NO is available at levels ranging from physiological to pathophysiological conditions. However, there are many other biological activities affected by NO (Brown, 2010; Thomas et al., 2008).

NO-sensitive sGCs, PKGs, and cGMP-regulated PDEs have important functions as generators, effectors, and modulators of cGMP signals in the brain, respectively. The $\mathrm{NO} / \mathrm{sGC} / \mathrm{cGMP} / \mathrm{PKG}$ pathway (Fig. 2) modulates long-term changes of synaptic activity in different brain regions. NO can modulate neuronal excitability and neurotransmitter release; thus, NO appears to play an important role in normal brain function and may have significant implications for the treatment of stress-related psychiatric disorders (Snyder \& Ferris, 2000; Chiavegatto \& Nelson, 2003). The human hippocampus contains a high density of NMDA receptors and neurons expressing nNOS suggesting that NMDA-NO transduction pathway can be involved in the pathogenesis of affective disorders and in the mechanism of action of antidepressants (Paul \& Skolnick, 2003). It is well established that nNOS-derived NO inhibits neurogenesis (Zhu et al., 2006); moreover, several studies have indicated that nNOS inhibitors have antidepressant-like properties (Joca \& Guimarães, 2006). Furthermore, several reports have demonstrated that increased plasma NO metabolites levels were associated with suicide attempts, especially in depressive patients (Kim et al., 2006; Lee et al., 2006). Activation of the NOS in the hippocampus can be involved in the pathogenesis of affective disorders, possibly triggered by effects of stress on hypothalamic-pituitary-adrenal (HPA) axis and mediated by impaired serotonin function.

\subsection{Phosphoinositide pathway}

Phosphoinositide pathway includes activation of phosphoinositide phospholipases C (PLCs), which participate in phosphatidylinositol bisphosphate $\left(\mathrm{PIP}_{2}\right)$ metabolism and lipid signalling pathways in a calcium-dependent manner (Fig. 3). PLCs are localized mostly in plasma membranes. PLC family contains 13 isoenzymes divided into six subfamilies. Neurotransmitter or agonist binds to receptor binding site and $G$ proteins (mostly $G_{q / 11}$, sometimes $\mathrm{G}_{\mathrm{o}}$ or $\left.\mathrm{G}_{\mathrm{i}}\right)$ are activated. $\mathrm{Ga}_{\mathrm{q} / 11}$ subunits activate $\left(\mathrm{Ca}^{2+}\right.$ is required) PLC, mostly PLC $\beta$ isoform. G $\beta$ Y subunits activate only isoenzymes PLC $\beta 2$ and PLC $\beta$ 3. PLC $\gamma$ subtype is activated by both receptor (trk) and non-receptor tyrosine kinases, PLC $\delta$ by elevated calcium levels, PLCe by Ras and Rho GTPases, PLCn by G $\beta \gamma$ subunits (Stewart et al., 2007). Activated PLCs catalyze hydrolysis of phosphatidylinositol 4,5-bisphosphate ( $\left.\mathrm{PIP}_{2}\right)$ and give arise to the second messengers inositol trisphosphate $\left(\mathrm{IP}_{3}\right)$ and diacylglycerol (DAG). DAG activates (in the presence of $\mathrm{Ca}^{2+}$ ) protein kinases type $\mathrm{C}$ (PKCs) and they phosphorylate many enzymes and other cellular proteins. $\mathrm{IP}_{3}$ binds to intracellular receptors $\left(\mathrm{IP}_{3} \mathrm{R}\right)$, leading to $\mathrm{Ca}^{2+}$ release from endoplasmic reticulum (ER). $\mathrm{Ca}^{2+}$ activates calmodulin (CaM), and $\mathrm{Ca}^{2+} / \mathrm{CaM}$-dependent protein kinases (CaMKs) phosphorylate a wide range of neuronal 


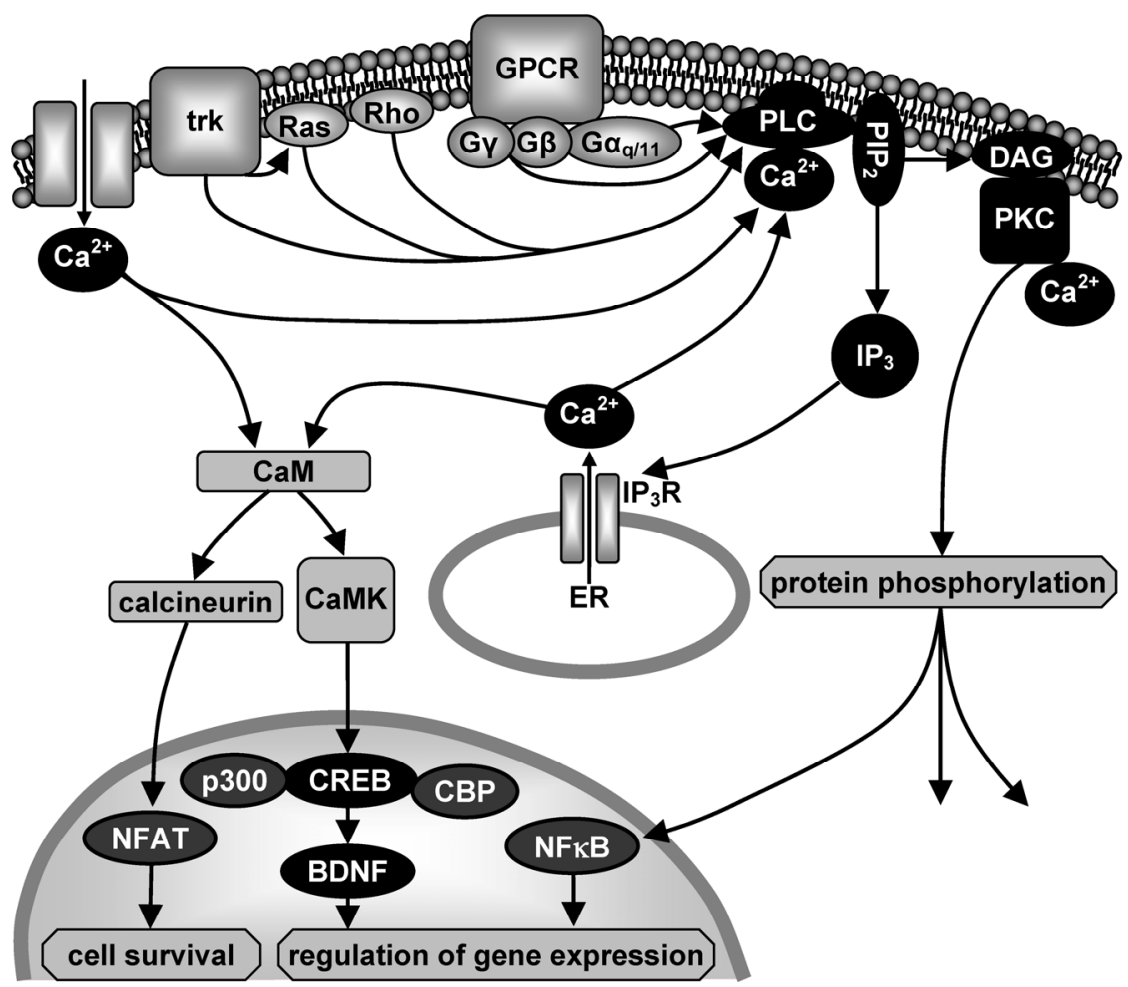

BDNF - brain-derived neurotrophic factor; CaM - calmodulin; CaMK - calcium and calmodulindependent protein kinase; CBP - CREB binding protein; CREB protein - cAMP response elementbinding protein; DAG - diacylglycerol; ER - endoplasmic reticulum; GPCR - G protein-coupled receptors; $\mathrm{IP}_{3}$ - inositol 1,4,5-trisphosphate; $\mathrm{IP}_{3} \mathrm{R}$ - $\mathrm{IP}_{3}$ receptor; $\mathrm{NF} \mathrm{KB}$ - nuclear factor $\mathrm{\kappa B}$; NFAT nuclear factor of activated T cells; p300 - transcriptional co-activating protein; $\mathrm{PIP}_{2}$ -

phosphatidylinositol 4,5-bisphosphate; PKC - protein kinase C; PLC - phosphoinositide phospholipase C, phospholipase C; Ras - small GTPase; Rho - small GTPase; trk - tropomyosin-related kinase; $\longrightarrow$ - activation; - inhibition

Fig. 3. Phosphoinositide pathway (Fišar \& Hroudová, 2010). Detailed description in the text.

proteins, including transcription factor CREB (with CBP and p300 as coactivators). Calcineurin, which dephosphorylates (activates) NFAT (nuclear factor of activated T cells) transcription factor, is also activated by CaM.

Nervous tissue shows high PKC activities; there this enzyme system takes part in the regulation of ion channels, modulation of receptors, release of neurotransmitters, synaptic potentiation, synaptic depression, neuronal survival etc. Changes of activities and concentrations of PKC isoforms have been described in neurodegenerative diseases both acute (ischemia, trauma) and chronic (Alzheimer's disease, Parkinson's disease, amyotrophic lateral sclerosis) and by affective or psychotic disorders (Battaini, 2001; Pascale et al., 2007). A large range of biochemical data supports potential PKC involvement in pathophysiology of bipolar disorder and its treatment. 


\subsection{Calcium signalling pathway}

Neurotransmitter, hormone or growth factor as well as depolarization of the membrane in excitable cells are responsible for change of intracellular calcium (Berridge et al., 2000). Intracellular calcium concentrations are regulated by transporters, which remove $\mathrm{Ca}^{2+}$ from the cell or store them in mitochondria and endoplasmic reticulum (Fig. 4). Intracellular calcium concentrations increase after the opening of $\mathrm{Ca}^{2+}$ channels in plasma membrane in the response to membrane depolarization (VOC, voltage-operated channel) or in response to activation of ionotropic receptors (ROC, receptor-operated channel; e.g. NMDA receptor) or in the response to activation of inositol trisphosphate receptor $\left(\mathrm{IP}_{3} \mathrm{R}\right)$ in the membrane of endoplasmic reticulum (ER). Concentrations of cytosolic calcium are decreased both by transport from cell and by uptake into the mitochondria or endoplasmic reticulum. Plasma membrane $\mathrm{Ca}^{2+}$-ATPases (PMCA), sodium-calcium exchanger (NCX) and mitochondrial calcium transporter (mCU) are responsible for the depletion of cytosolic calcium. Mitochondrial NCX in reverse mode of operation participates in the influx of $\mathrm{Ca}^{2+}$ ions into matrix in pathological conditions such as brain ischemia. Following $\mathrm{Ca}^{2+}$ uptake into the mitochondria, $\mathrm{Ca}^{2+}$ is slowly released by mitochondrial NCX (Kann \& Kovács, 2007). $\mathrm{Ca}^{2+}$ can be released also from ER, by $\mathrm{Ca}^{2+}$-activation of ryanodine receptor (RyR).

Increased cytoplasmic calcium activates calmodulin (CaM) and consequently both calcineurin and $\mathrm{Ca}^{2+}$ - and CaM-dependent protein kinases (CaMK) are activated. Cascade of calcium and $\mathrm{CaM}$ dependent protein kinases includes three kinases: kinase of CaM kinase (CaMKK) and CaM kinases CaMKI and CaMKIV which are activated by CaMKK. They occur frequently in the brain and T-lymphocytes. Nuclear CaMKIV regulates transcription through the phosphorylation of transcription factors, including CREB protein. Crossconnections of these protein kinases with other signalling pathways exist in the cytoplasm, e.g. with PKA, mitogen activated protein kinases (MAPK), and Akt (PKB). Consequently, CaMK are connected to the processes related to neuroplasticity and neuronal protection against apoptosis (Berridge et al., 2000; Miyamoto, 2006; Soderling, 1999).

Calcineurin dephosphorylates nuclear factor of activated T cells (NFAT), which afterwards enters into the nucleus and completes NFAT transcription complexes; these complexes regulate expression of growth factors, cytokines and other molecules essential for morphogenesis, development and function of neurons and other cells. Stimulus activating NFAT signalling pathway may originate from receptors with tyrosine kinase activity, ion channels, non-receptor tyrosine kinases, G protein-coupled receptors, and gap junctions (Wu et al., 2007). Other targets of calcium are adenylate cyclases (AC), some of them are activated others are inhibited. Further, $\mathrm{Ca}^{2+}$ stimulates some of cAMP phosphodiesterases (PDEs) resulting in changes of cAMP concentration; cAMP concentrations affect calcium levels through the activation of $\mathrm{Ca}^{2+}$-channels or pumps by protein kinase A (PKA).

Activation of nitric oxide synthase (NOS) is an important role of $\mathrm{Ca}^{2+}$. NOS enables $\mathrm{NO}$ production, activation of sGC and cGMP production; the cGMP influences activity of $\mathrm{Ca}^{2+}$ channels and pumps (feedback). Phosphoinositide-3-kinase (PI3K) interferes in the calcium pathways through the production of phosphatidylinositol 3,4,5-trisphosphate $\left(\mathrm{PIP}_{3}\right)$, which activates non-receptor tyrosine kinase Btk consequently activating $\mathrm{PLC}_{\gamma} 1$, and $\mathrm{IP}_{3}$ is produced. Increased $\mathrm{Ca}^{2+}$ concentrations also activate PLC $\delta$ which increases $\mathrm{IP}_{3}$ concentrations. Conversely, $\mathrm{Ca}^{2+}$ can decrease $\mathrm{IP}_{3}$ production by the activation of $\mathrm{IP}_{3}-\mathrm{kinase}$ $\left(\mathrm{IP}_{3} \mathrm{~K}\right)$. Calcium activates tyrosine kinases enriched with proline (PYK2), which activate 


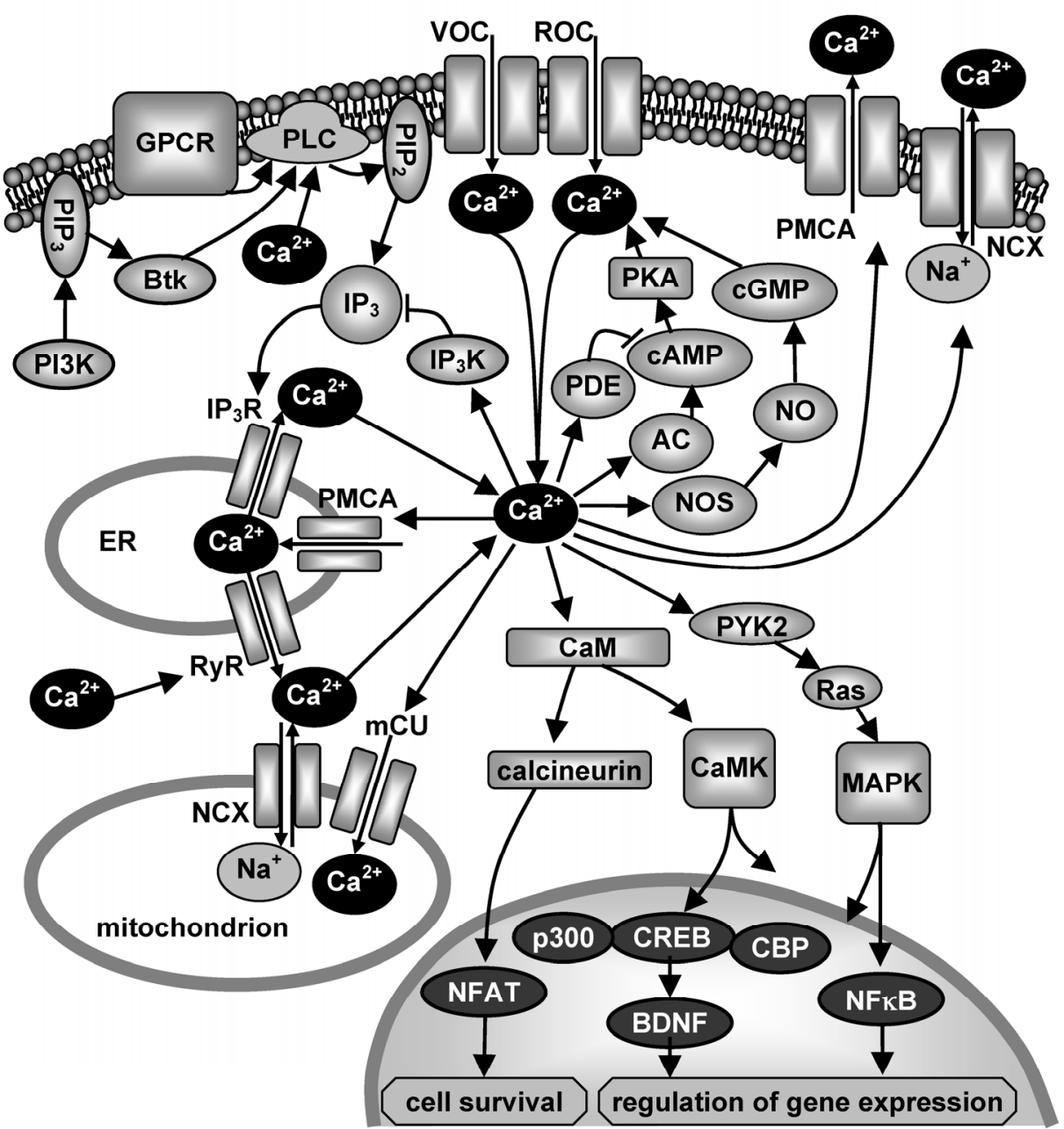

AC - adenylate cyclase (adenylyl cyclase); BDNF - brain-derived neurotrophic factor; Btk - Bruton tyrosine kinase; CaM - calmodulin; CaMK - calcium and calmodulin-dependent protein kinase; cAMP cyclic adenosine monophosphate; CBP - CREB binding protein; CREB protein - cAMP response elementbinding protein; cGMP - cyclic guanosine monophosphate; ER - endoplasmic reticulum; GPCR - G protein-coupled receptors; $\mathrm{IP}_{3}$ - inositol 1,4,5-trisphosphate; $\mathrm{IP}_{3} \mathrm{~K}$ - IP 3 kinase; $\mathrm{IP}_{3} \mathrm{R}$ - $\mathrm{IP}_{3}$ receptor; $\mathrm{MAPK}$ mitogen-activated protein kinase; $\mathrm{mCU}$ - mitochondrial $\mathrm{Ca}^{2+}$ uniporter; $\mathrm{NCX}-\mathrm{Na}^{+} / \mathrm{Ca}^{2+}$ exchanger; $\mathrm{NFKB}$ - nuclear factor $\mathrm{kB}$; NFAT - nuclear factor of activated T cells; NO - nitric oxide; NOS - nitric oxide synthase; p300 - transcriptional co-activating protein; PDE - phosphodiesterase; PI3K - phosphoinositide 3-kinase; $\mathrm{PIP}_{2}$ - phosphatidylinositol 4,5-bisphosphate; $\mathrm{PIP}_{3}$ - phosphatidylinositol 3,4,5-trisphosphate; PKA - protein kinase A, cAMP dependent protein kinase; PLC - phosphoinositide phospholipase C, phospholipase C; PMCA - plasma membrane $\mathrm{Ca}^{2+}$ ATPase; PYK2 - tyrosine kinase enriched with proline; ROC - receptor-operated channel; RyR - ryanodine receptor; VOC - voltage-operated channel; $\longrightarrow$ activation; - inhibition

Fig. 4. Calcium signalling pathway (Fišar \& Hroudová, 2010). Detailed description in the text. 
small GTPases Ras and mitogen-activated protein kinases (MAPKs). Protein kinases phosphorylate cellular proteins, which results in the cellular response to elevated $\mathrm{Ca}^{2+}$ concentrations, including induction of gene expression.

\subsection{Wnt pathway}

The Wnt signalling pathway activated by Wnt growth factors describes a complex of processes well known for their roles in embryogenesis and cancer, but also involved in normal physiological processes and in regulation of adult hippocampal neurogenesis (Clevers, 2006; Fuerer et al., 2008; Lie et al., 2005). Wnt signals are transmitted at least by three intracellular pathways; the most investigated one is canonical Wnt signalling pathway, which primarily modulates cellular processes during the cell development.

The canonical Wnt pathway (Fig. 5) describes a series of events occurring when Wnt glycoproteins bind to transmembrane receptor of the Frizzled family (WntR); membrane

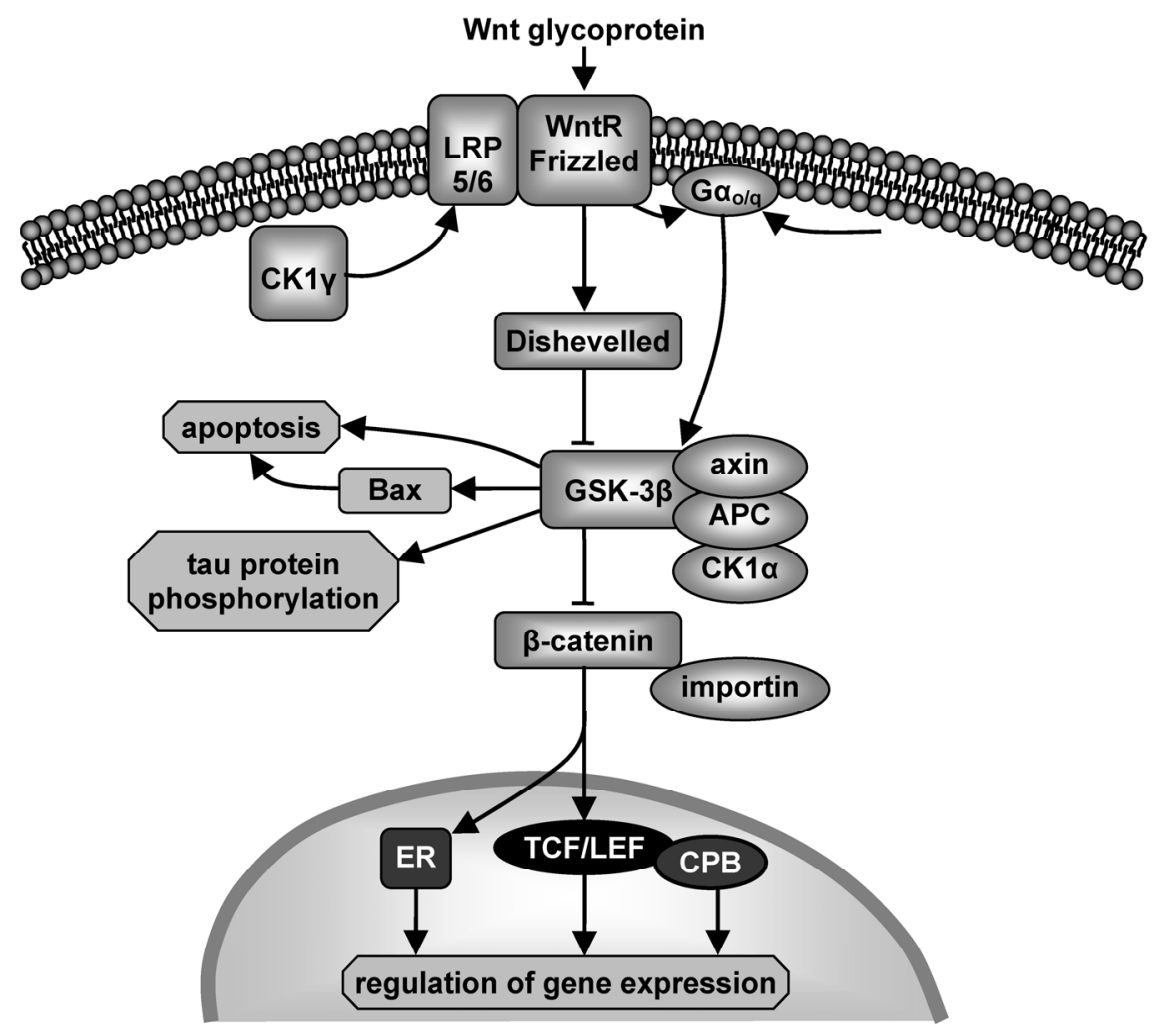

APC - adenomatous polyposis coli; Bax - proapoptotic factor from Bcl-2 family; CBP - CREB binding protein; CK - casein kinase; ER - estrogen receptor; GSK-3 $\beta$ - glycogen synthase kinase- $3 \beta$; LEF lymphoid-enhancing factor; LRP 5/6 - transmembrane protein; TCF - T cell factor; WntR - Wnt receptor (transmembrane receptor of the Frizzled family); $\longrightarrow$ - activation; $\longrightarrow$ - inhibition Fig. 5. Canonical Wnt pathway (Fišar \& Hroudová, 2010). Detailed description in the text. 
protein LRP $5 / 6$ phosphorylated by casein kinase $1 \gamma(\mathrm{CK} 1 \gamma)$ participates in the binding. Signal is transferred on the cytoplasmic protein Dishevelled that increases phosphorylation of glycogen synthase kinase-3 $\beta$ (GSK-3 $\beta$ ). Therefore, complex of proteins that includes GSK$3 \beta$, axin, protein APC (adenomatous polyposis coli) and casein kinase 1a (CK1a) is inhibited, because phosphorylation of both of axin and $\beta$-catenin (mediated by GSK-3 $\beta$ ) is decreased, and non-phosphorylated axin is degraded (Lee et al., 2003). It is suggested that heterotrimeric $\mathrm{G}$ proteins participate in disturbance of interaction GSK-3 $\beta$ with axin; some of these $G$ proteins are probably associated with WntR (Liu et al., 2005). If the GSK-3 $\beta$ /axin complex is not inhibited, $\beta$-catenin is phosphorylated by CK1 $\alpha$ and GSK-3 $\beta$ and $\beta$-catenin is degraded. If $\beta$-catenin is not degraded, it accumulates in cytoplasm and is transported by importin into the nucleus. Main target of $\beta$-catenin in the nucleus is transcription factor TCF ( $\mathrm{T}$ cell factor) from LEF (lymphoid-enhancing factor) family; connection of TCF and $\beta$ catenin leads to activation of transcription factor. TCF, $\beta$-catenin and other transcription cofactors, such as CREB binding protein (CBP), activates the transcription of target genes. $\beta$ catenin activated by Wnt pathway interacts also with estrogen receptor (ER) and other nuclear receptors. Inhibition of GSK-3 $\beta$ links Wnt pathway also with apoptosis (through the activation of proapoptotic factor Bax from Bcl-2 family) and Alzheimer's disease (through tau protein phosphorylation). Recently, this pathway has been linked to therapeutic effects of lithium administered at bipolar disorders, probably through the activation of transcription factors by $\beta$-catenin.

\subsection{Tyrosine kinase pathway}

Tyrosine kinase pathway is activated by growth factors. Binding of neurotrophin to its trk receptor leads to three consequent processes (Fig. 6):

1. Receptor's autophosphorylation leads to phosphorylation of SHC protein, on which complex GRB2 (growth factor receptor bound protein-2)-SOS (son of sevenless protein) is attached to the membrane. SOS activates small G protein Ras and it attaches Raf kinase to the membrane. Activated Raf phosphorylates mitogen-activated protein kinase kinases MEK1, MEK2 or MEK5, and activated MEKs phosphorylate extracellular signal-regulated kinases (ERKs). G protein-coupled receptors are involved also in the ERK activation, namely by the activation of protein kinases PKA or PKC that activate Raf, consequently ERKs are activated. Activated ERK1 and ERK2 are transported into the nucleus and phosphorylate nuclear targets there, especially transcription factor Elk1 and kinase RSK (ribosomal protein S6 kinase). RSK has a principal role in regulation of gene transcription, because of its phosphorylation of a range of various factors. Phosphorylated Elk1 interacts with SRF (serum response factor) transcription factor, and transcription is initiated after the binding of a relevant response element in the area of c-Fos promoter. Phosphorylated RSK enables CREB phosphorylation; it binds to CREB binding protein (CBP) and to SRF/Elk1 complex, which leads to c-Fos transcription. As a result, there is regulation of immune and inflammatory processes, and control of cell growth and apoptosis. ERK5 is phosphorylated and activated by MEK5 (kinase of MAP kinase). In the contrast to ERK1 and ERK2, ERK5 is activated only by neurotrophins. ERK5 is included in cell survival through the MEF2 (myocyte enhancer factor 2) substrate (Wada \& Penninger, 2004).

2. Phosphorylation of phospholipase $C_{\gamma}$ (PLC $\left.\gamma\right)$ by trk receptor enables catalysis of phosphatidylinositol 4,5-bisphosphate $\left(\mathrm{PIP}_{2}\right)$ cleavage to diacylglycerol (DAG) and 


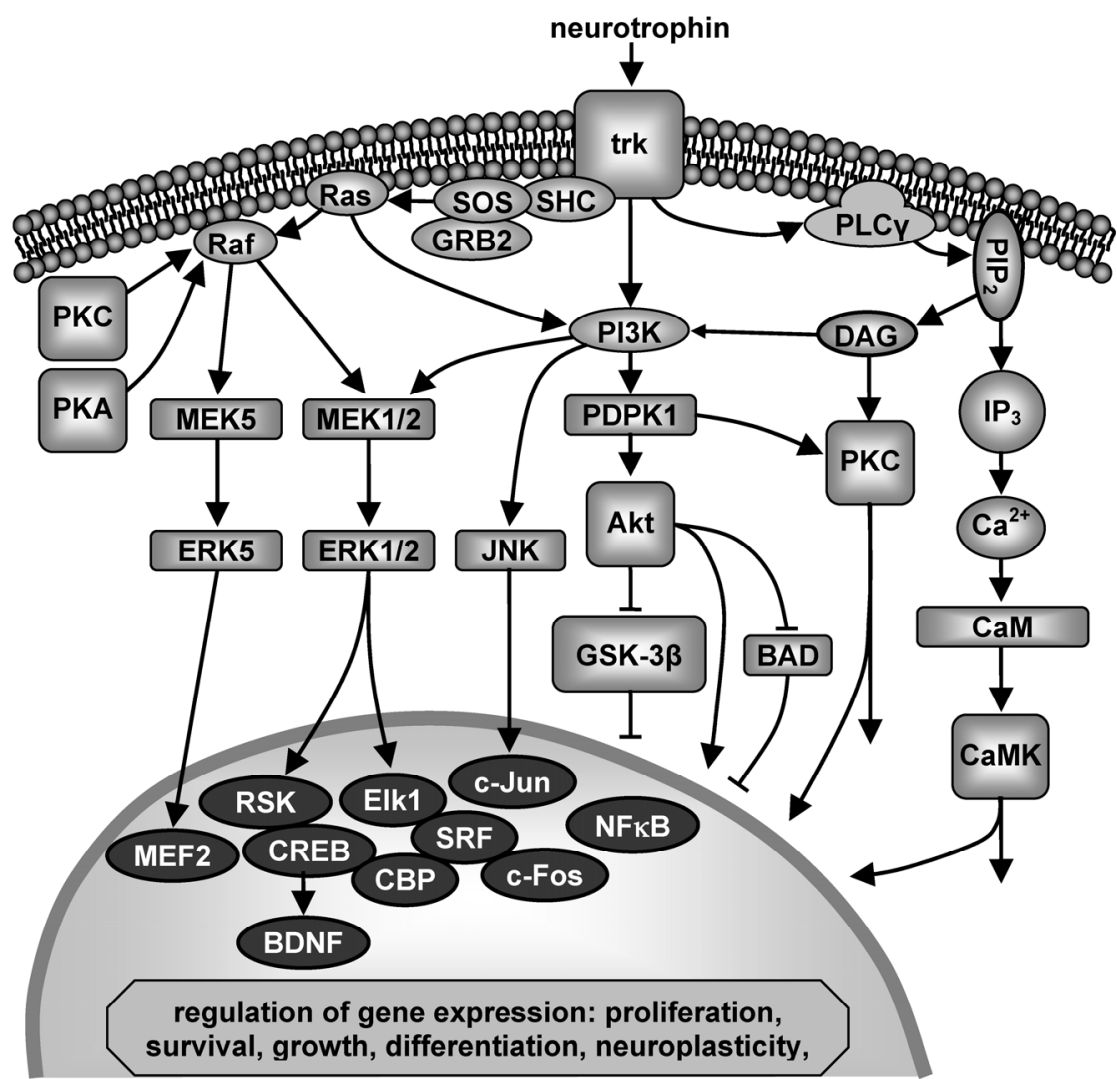

Akt - protein kinase B (PKB); BAD - proapoptotic factor (Bcl-2-associated death promoter); BDNF brain-derived neurotrophic factor; CaM - calmodulin; CaMK - calcium and calmodulin-dependent protein kinase; CBP - CREB binding protein; c-Fos - transcription factor; c-Jun - transcription factor; CREB protein - cAMP response element-binding protein; DAG - diacylglycerol; Elk1 - transcription factor; ERK - extracellular signal-regulated kinase; GSK-3 $\beta$ - glycogen synthase kinase-3 $\beta$; $\mathrm{IP}_{3}$ - inositol 1,4,5-trisphosphate; JNK - c-Jun $N$-terminal kinase (stress-activated protein kinase); MEF2 - myocyte enhancer factor 2; MEK - mitogen-activated protein kinase kinase; NFKB - nuclear factor кB; PDPK1 3-phosphoinositide dependent protein kinase-1; PI3K - phosphoinositide 3-kinase; $\mathrm{PIP}_{2}$ phosphatidylinositol 4,5-bisphosphate; PKA - protein kinase A; PKC - protein kinase C; PLC phosphoinositide phospholipase C; Raf - protein kinase ; Ras - small GTPase; RSK - ribosomal protein S6 kinase; SHC - protein with SH2 domain; SOS - son of sevenless protein; SRF - serum response factor; trk - tropomyosin-related kinase; $\longrightarrow$ - activation; $\longrightarrow$ - inhibition

Fig. 6. Tyrosin kinase pathway (Fišar \& Hroudová, 2010). Detailed description in the text.

inositol trisphosphate $\left(\mathrm{IP}_{3}\right)$. DAG can activate phosphoinositide-3-kinase (PI3K) or various protein kinases $\mathrm{C}(\mathrm{PKCs}) . \mathrm{IP}_{3}$ releases calcium from intracellular stores and it activates calmodulin $(\mathrm{CaM})$ and $\mathrm{Ca}^{2+} / \mathrm{CaM}$-dependent protein kinases (CaMKs).

3. Phosphatidylinositol 3,4,5-trisphosphate $\left(\mathrm{PIP}_{3}\right)$ is formed after the stimulation of PI3K heterodimers, which activates kinase PDPK1 (3-phosphoinositide dependent protein kinase-1) and therefore, protein kinase Akt (also known as PKB) is activated. Akt 
supports survival and differentiation of neurons both by stimulation of transcription factors and by inhibition of proapoptotic factor BAD or glycogen synthase kinase- $3 \beta$ (GSK-3 $\beta$ ). PI3Ks activate also PKC $\zeta$ or they can indirectly activate protein kinases JNK (c-Jun $N$-terminal kinases), which are responsible for c-Jun phosphorylation and initiation of apoptosis (Cowan \& Storey, 2003).

\section{Neuroplasticity}

Neuroplasticity is a fundamental mechanism of neuronal adaptation to environmental inputs. The term neuroplasticity (brain plasticity, cortical plasticity, cortical re-mapping) is used for description of either functional or structural changes of neurons and glial cells that occur in developing brain as well as in the adult brain in order to adjust to external or internal stimuli (Mesulam, 1999; Nestler et al., 2002). The most widely recognized forms of plasticity are learning, memory, and recovery from nervous system injury, which may happen through the change in the strength of connections among brain cells, by adding or removing connections, or by adding new cells.

Neuroplasticity is linked to the concept of synaptic pruning (neuronal pruning, neurostructural reassembly), defined as regulatory processes, which facilitate a productive change in neural structure by reducing the overall number of neurons or connections, leaving more efficient synaptic configurations; really, excess of neurons was observed in the human newborn mediodorsal thalamus compared with that of the adult (Abitz et al., 2007). New findings suggest that all areas of the brain are plastic even after childhood. Neuroplasticity in the adult brain includes changes of dendritic functions, reorganization of synapses, long-term potentiation (LTP), long-term depression (LTD), branching and sprouting of axons and dendrites, synaptogenesis, and neurogenesis (Fišar \& Hroudová, 2010). Environmental changes could alter behaviour and cognition by adapting connections between neurons, and neurogenesis may be included in these processes. It is possible that there is a link between neurogenesis and learning-related changes in the brain. Adult neurogenesis in mammals is mainly restricted to the hippocampus and olfactory bulb; current research has revealed that other parts of the brain, the cerebellum included, may be also involved (Ponti et al., 2008). However, the reorganisation of the complex brain networks is not always beneficial for the individual. Maladaptive plasticity can be defined as behavioural loss or as development of disease symptoms resulting from plasticity changes in the adult brain (Draganski \& May, 2008).

The development of new synapses, the activity dependent changes in the strength of existing synapses and the elimination of synapses have been proposed to form basis of synaptic plasticity. The synaptic plasticity could be the cellular basis of certain forms of learning and memory (Citri \& Malenka, 2008). Synaptic plasticity has been studied in many brain regions, the most frequently in the hippocampus.

Recently, the concept was modified that synapse-specific forms of LTP and LTD at excitatory synapse can fully explain learning and experience-dependent plasticity. Intrinsic, inhibitory, and homeostatic plasticity were documented as additional forms of plasticity (Nelson \& Turrigiano, 2008). A novel form of persistent synaptic plasticity was called metaplasticity (the plasticity of synaptic plasticity). Metaplasticity is induced by synaptic or cellular activity, but is not necessarily expressed as a change in the efficacy of normal 
synaptic transmission. Instead, it is manifested as a change in the ability to induce subsequent synaptic plasticity, such as LTP or LTD. Thus, metaplasticity is a higher-order form of synaptic plasticity (Abraham \& Bear, 1996).

There is both postsynaptic and presynaptic plasticity. Postsynaptic plasticity involves changes in the number or sensitivity of postsynaptic receptors without any changes in the amount of neurotransmitter release. Basic mechanisms of postsynaptic plasticity are connected with activation of postsynaptic NMDA receptors followed by $\mathrm{Ca}^{2+}$ influx; calcium triggers following mechanisms contributing to synaptic plasticity in spines: 1 . The regulation of channels and proteins involved in trafficking, cytoskeletal organization and protein synthesis; 2. Alterations of synaptic AMPA receptor properties, subunit composition and trafficking; 3. Actin reorganization and modulation of spine morphology; and 4. Initiation of local protein synthesis in spines and dendrites (Derkach et al., 2007).

Presynaptic plasticity generally translates into an increase or a decrease of neurotransmitter release (García-Junco-Clemente et al., 2005). Presynaptic plasticity has the potential to greatly influence all of the neurotransmitters release sites within a given axon, such that changes in the output of one inhibitory interneuron could modify the activity of many of its downstream target neurons (Tóth \& McBain, 2000). Mechanisms of presynaptic LTP or LTD may be independent on NMDA receptors. It is hypothesized that various forms of presynaptic plasticity can operate in a manner fundamentally distinct from most postsynaptic forms of plasticity (García-Junco-Clemente et al., 2005; McBain \& Kauer, 2009). A new class of presynaptic plasticity that requires signalling by endocannabinoids has been identified in several brain structures (Chevaleyre et al., 2006). At many of these synapses presynaptically expressed forms of LTD can coexist with postsynaptic forms of LTD mediated by internalization of AMPA receptors (Nelson \& Turrigiano, 2008).

Learning and memory depend on long-lasting changes in synaptic strength. Long-term synaptic plasticity changes last from hours to weeks. These changes require induction of gene expression, production and insertion of new proteins. Activation of $\beta$-adrenoceptors can enhance LTP and facilitate long-term memory storage. Cyclic AMP/PKA and extracellular signal-regulated protein kinase cascades are important to express the longlasting LTP in hippocampus, amygdala, and cortex (Pittenger \& Duman, 2008). Transcription factor CREB is particularly important in modulation of synaptic plasticity. CREB is activated (phosphorylated) by PKA and other kinases upon synaptic stimulation during learning (Carlezon et al., 2005).

\section{Stress, HPA axis and glutamate neurotoxicity}

Stress may be defined as any environmental change, whether internal or external, that disturbs homeostasis (Leonard \& Myint, 2009). Stress system is located in both the central nervous system and peripheral organs. Central functions of the stress response include facilitation of arousal, alertness, cognition, attention and aggression, inhibition of vegetative functions, and activation of counter-regulator feedback loops. Peripheral functions include increase of oxygenation, nutrition of the brain, hearth and skeletal muscles, increase of cardiovascular tone and respiration, increase of metabolism and detoxification, and activation of counter-regulatory feedback loops (Chrousos, 2009). 
Stress activates both hypothalamic-pituitary-adrenal (HPA) axis and the sympathetic nervous system. The main central effectors of stress system include corticotrophin-releasing factor (CRF), arginine vasopressin (AVP) and norepinephrine. Chronic stress, as a result of the hypersecretion of cortisol, causes a decrease in serotonin turnover partly as a consequence of increased metabolism of tryptophan (Leonard \& Myint, 2009). Increased activity of the HPA axis has been reported not only after stress but also in pregnancy and in many diseases, such as Cushing syndrome, depression, anorexia nervosa, obsessivecompulsive disorder, panic disorder, alcoholism, diabetes mellitus, metabolic syndrome, hyperthyroidism, etc. (Chrousos, 2009).

Stressors provoke the secretion of epinephrine and norepinephrine by the sympathetic nervous system, to induce the flight-or-fight response, and of the glucocorticoids by the adrenal gland. Catecholamine action involves activation of $\beta$-adrenoceptors and initiation of second messenger cascades in target cells within seconds; whereas, glucocorticoid's effects can take hours to emerge, as they involve transcriptional events. Brain areas involved in the stress response include the prefrontal cortex, the hippocampus, and the amygdala; they undergo stress-induced remodelling, which alters behavioural and physiological responses (McEwen, 2007). Many central aspects of stress response are modulated, and in some cases mediated, by glutamate neurotransmission in the prefrontal cortex (Moghaddam, 2002).

Stress and stress hormones produce both adaptive and maladaptive effects in the brain (McEwen, 2007). It is known that stress is important contributor to psychosocial and physical disorders. The relationship between stressful life events and development of mood disorders in vulnerable subjects has been long established (Aguilera et al., 2009; Caspi et al., 2003; Johnson, 2005; Kendler et al., 1999). Adverse childhood experiences have been described as one of the major environmental risk factors for depressive disorder.

Acute and chronic stress can have quite different effects on neuroplasticity. The mild stress for a few hours can enhance cognition by facilitating aspects of synaptic plasticity in the hippocampus; these effects are mediated by high-affinity corticosteroid receptors. In contrast, excessive glucocorticoid exposure in the hippocampus as a result of major and prolonged stress can be directly toxic to neurons, or can increase the neurotoxicity of various hippocampal insults (Lee et al., 2002; McEwen \& Sapolsky, 1995; Sapolsky, 1996).

Stress produces a rapid increase in glutamate efflux in the prefrontal cortex and the hippocampus (Moghaddam, 2002). An excess of glutamate in the synapse leads to excess of cytosolic calcium, which produce overactivity of calcium-dependent enzymes and it leads to cytoskeletal degradation, protein malformation and oxygen radical generation. These processes can lead to atrophy or death of neurons (Atlante et al., 2001; Lipton, 1999). Different insults, such as hypoxia-ischemia, seizure and hypoglycaemia, all of them activate this pathway.

Neurons mobilize a variety of defences when are challenged with glutamatergic insults, e.g. removal of glutamate from the synapse, and of calcium from the cytoplasm, production of heat shock proteins (HSP), protective hyperpolarisation, and protective upregulation of antioxidant enzymes (Lee et al., 2002). The glia cells account for the majority of glutamate uptake.

Processes accompanying neuroplasticity are extremely energy-consuming and interfere with different intracellular pathways included in signal transduction or in apoptosis. Thus, it 
seems to be useful to study the mitochondrial dysfunctions in relation to neuroplasticity, mechanisms of stress response, pathophysiology of mood disorders, and mechanisms of action of psychotropic drugs, antidepressants and mood stabilizers included (Hroudová \& Fišar, 2011). It was proposed that subtle deficits in the mitochondrial function likely play an important role in various facets of bipolar disorder, and that enhancing mitochondrial function may represent a critical component for the optimal treatment of the disorder (Quiroz et al., 2008).

There are close relationships between the mechanisms of synaptic plasticity, effects of stress, mechanisms of antidepressant action, and pathophysiology of depression (Pittenger \& Duman, 2008). In order to explain these relationships, interactions among signal transduction pathways have been studied (Fišar \& Hroudová, 2010; Hroudová \& Fišar, 2011), including the role of mitochondria (Fig. 7).

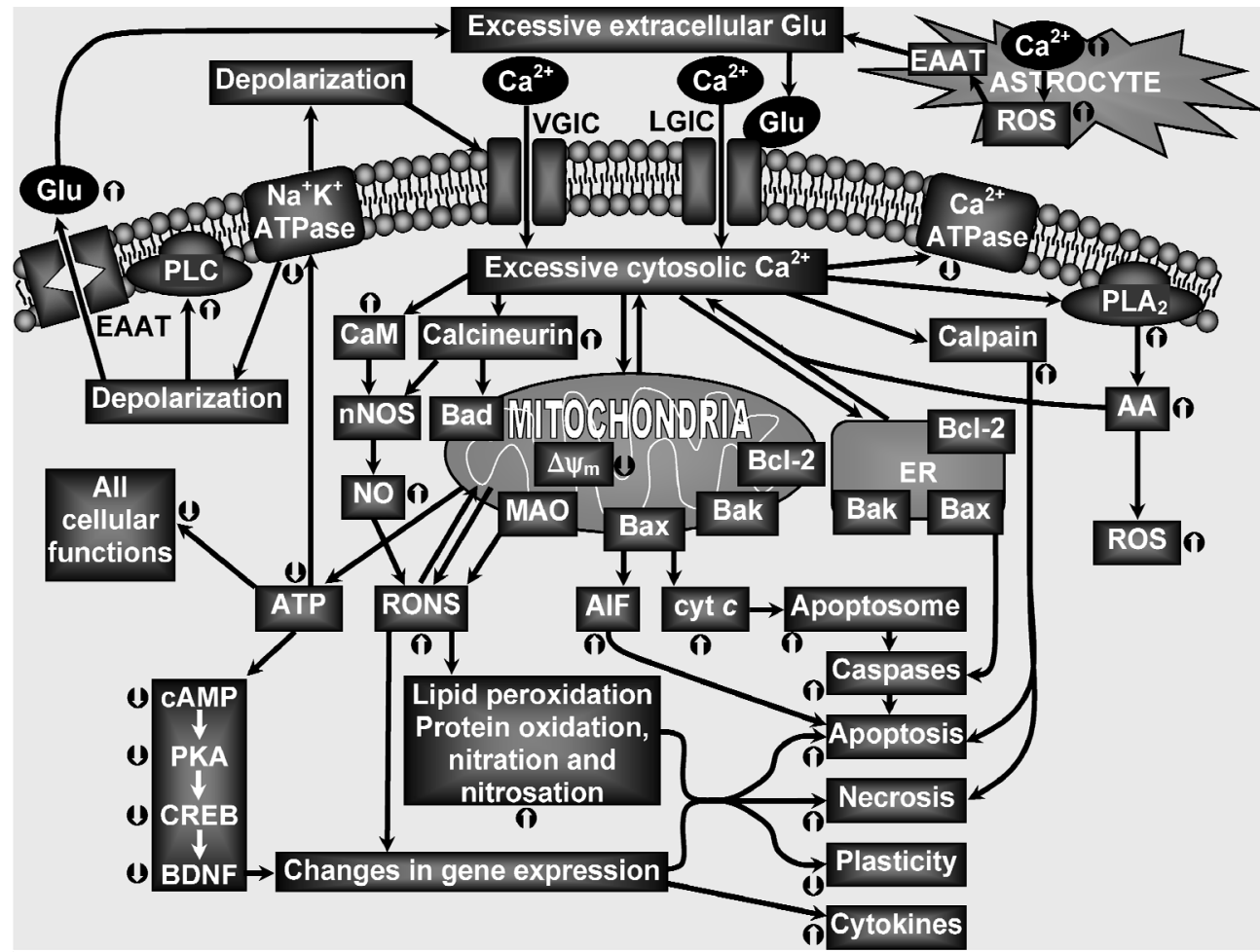

AA - arachidonic acid; ATP - adenosine-5'-triphosphate; Bax, Bak, BAD - proapoptotic factors of Bcl-2 family; Bcl-2 - antiapoptotic factor of Bcl-2 family; BDNF - brain-derived neurotrophic factor; CaM calmodulin; cAMP - cyclic adenosine monophosphate; CREB - cAMP response element-binding; $\Delta \psi \mathrm{m}$ potential on the inner mitochondrial membrane; EAAT - excitatory amino acid transporter; ER endoplasmic reticulum; Glu - glutamate; $\mathrm{MAO}$ - monoamine oxidase; nNOS - neuronal nitric oxide synthase; $\mathrm{NO}$ - nitric oxide; PKA - protein kinase A; PLA $\mathrm{A}_{2}$ - phospholipase $\mathrm{A}_{2} ; \mathrm{PLC}$ - phospholipase C; ROS - reactive oxygen species; RONS - reactive oxygen and nitrogen species

Fig. 7. Principal mechanisms of glutamate neurotoxicity (Hroudová \& Fišar, 2011). Detailed description in the text. 
Principal mechanisms leading to neuronal impairment and cell death are composed of

1. Decreased adenosine triphosphate (ATP) production;

2. Increased production of reactive oxygen and nitrogen species (RONS);

3. Initiation of apoptotic processes;

4. Impaired calcium homeostasis.

Decrease of ATP production leads to impairment of ATP-dependent processes and therefore to changed cellular functions (Fig. 7). Insufficient function of $\mathrm{Na}^{+} \mathrm{K}^{+}-$ATPases leads to membrane depolarization. Membrane depolarization changes the functions of amino acids transporters and increases concentration of extracellular glutamate. Voltage-gated ion channels (VOC) and/or ligand-dependent calcium channels (ROC) are activated and mediate calcium influx. Intracellular calcium causes functional changes of amino acid transporters, enhances extracellular glutamate and extends neurotoxicity. Increased levels of synaptic glutamate can be mediated also by release of glutamate from astrocytes. The activation of ionotropic glutamate receptors leads to higher calcium influx into the cell, which is followed by increased activation of phospholipases, proteases, and endonucleases. For example, activation of phospholipase $\mathrm{A}_{2}\left(\mathrm{PLA}_{2}\right)$ by calcium releases membrane arachidonic acid (AA), which induces production of superoxide.

High intracellular calcium levels induce overload of mitochondrial calcium, leading to increase of reactive oxygen species (ROS) production and inhibition of ATP production. Activation of calcium-dependent protein phosphatases (e.g. calcineurin) causes translocation of proapoptotic factor BAD into the mitochondria and triggers apoptosis by sequestration of antiapoptotic factors Bcl-2 and Bcl-xL. Release of cytochrome $c$ (cyt $c$ ) and other proapoptotic factors from the intermembrane space of mitochondria induces the formation of apoptosome, and consequently triggers activation of caspases and apoptosis. Apoptosis-inducing factor (AIF) is another factor released by mitochondria. Mitochondria in the brain are also a target of nitric oxide (NO) action.

\section{Mechanisms of action of antidepressants and mood stabilizers}

Current antidepressant medications are effective in about $60 \%$ of treated patients (Nelson, 1999; Papakostas et al., 2007) and significant therapeutic response is observed after several weeks of treatment. Thus, faster and more effective pharmacological treatments for depressive disorders are greatly needed.

Biochemical effects of antidepressants and mood stabilizers are studied with the aim to discover both molecular mechanism of their therapeutic efficiency and neurochemical nature of mood disorders. Both complex clinical pattern of mood disorders and adaptive changes in activity or availability of a large number of components of signalling pathways after long-term treatment with antidepressants is responsible for the fact, that definite molecular mechanisms responsible for therapeutic action of drugs are not known.

It seems that psychotropic drugs used in the therapy of mood disorders show neurotrophic or neuroprotective effects after long-term treatment. Thus, next to adenylate cyclase, guanylate cyclase, phosphoinositide and calcium systems, attention has been paid to tyrosine kinase pathway, Wnt pathway and inflammatory pathway. 


\subsection{Antidepressants}

Antidepressants are psychiatric medication used to treatment of mood disorders, such as major depression, dysthymia, and anxiety disorders. Easily 41 drugs are currently used as antidepressants worldwide and many other drugs are administered as supportive therapy or holding course. At the level of chemical synapses, antidepressants usually act as serotonin or norepinephrine reuptake inhibitors, as inhibitors of the degradation of monoamine neurotransmitters, or as agonists or antagonists of their receptors. Therefore, the administration of antidepressants induces increased concentrations of norepinephrine and serotonin in the synaptic cleft. Consequently, increased activation or inhibition occurs in processes of intracellular signalling pathways, mainly in adenylate cyclase and phosphoinositide pathway.

Clinical effects of antidepressants are obviously caused by their ability to induce adaptive changes in neurotransmission, mainly serotonergic and noradrenergic. Changes in the availability of neurotransmitters and also in the density and sensitivity of their receptors and transporters are not sufficient to explain origin and course of the mood disorders neither the mechanisms of action of antidepressants and mood stabilizers. It was supposed that intracellular processes included in apoptotic, neurodegenerative, and inflammatory pathways are responsible for final therapeutic effects (Porcelli et al., 2011).

Antidepressants are currently classified according to their direct biochemical effects, which are well known in comparison with their long-term effects. The first antidepressants were monoamine oxidase inhibitors (MAOIs) and nonselective serotonin and/or norepinephrine reuptake inhibitors referred to as tricyclic antidepressants (TCAs). MAOIs act as antidepressants by blocking of enzyme that degrades monoamine neurotransmitters; TCAs act as antidepressants by blocking membrane transporters ensuring reuptake of 5-HT or NE, thus cause increased extracellular neurotransmitter concentrations. Next generations of antidepressants include selective serotonin reuptake inhibitors (SSRIs), norepinephrine reuptake inhibitors (NRIs), serotonin-norepinephrine reuptake inhibitors (SNRI), noradrenergic and specific serotonergic antidepressants (NaSSAs), serotonin antagonist and reuptake inhibitors (SARIs), norepinephrine-dopamine reuptake inhibitors (NDRIs), melatonin receptors agonist and selective serotonin antagonist (MASSA), sigma receptors agonist, and drugs directly affecting the neuroplasticity renewal. However, other classes of antidepressants may be suggested; e.g. antagonists of $5-\mathrm{HT}_{2 \mathrm{C}}$ receptors may be classified as norepinephrine-dopamine disinhibitors (NDDIs), because they act by antagonizing receptors that normally acts to inhibit norepinephrine and dopamine release. Tianeptin was initially classified as selective serotonin reuptake enhancer (SSRE); however, its affinity to serotonin transporter is low and it was supposed that its therapeutic action is related to restore normal neuroplasticity in circumscribed limbic brain regions and to reverse stressinduced impairments in synaptic glutamate transmission (McEwen et al., 2010). It is of interest that new psychotropic drugs are multifunctional, i.e. agents with more than one putative therapeutic mechanism of action (Stahl, 2009).

\subsubsection{Effect on glutamate system}

Antidepressants affect learning and memory in animal models and enhance structural plasticity and hippocampal neurogenesis (Drzyzga et al., 2009; Kasper \& McEwen, 2008; 
Warner-Schmidt \& Duman, 2006). Antidepressants can directly modulate glutamatergic neurotransmission through NMDA or AMPA receptors; it is likely that an intimate relationship exists between regulation of monoaminergic and glutamatergic neurotransmission and antidepressant effects (Paul \& Skolnick, 2003). As mentioned above, tianeptine prevents or reverses stress-associated structural and cellular changes in the brain and normalizes disrupted glutamatergic neurotransmission in the hippocampus, the amygdala, and the cortex (Kasper \& McEwen, 2008; McEwen et al., 2010). An inhibition of an excessive release of glutamate appears to be important for mechanisms of action of lamotrigine and riluzole (Zarate et al., 2006a). Robust and rapid antidepressant effect on individuals with treatment-resistant depression resulted from a single intravenous dose of ketamine (a non-competitive NMDA receptor antagonist and psychomimetic) (Diazgranados et al., 2010; Zarate et al., 2006b). These effects suggest that depressive symptoms can be improved by altering the action of glutamate (Krishnan \& Nestler, 2008).

\subsubsection{Effect on neuroplasticity and neurogenesis}

Time-dependent therapeutic effects of antidepressants could be related to changes in gene expression in the brain. If a deficit in neuroplasticity is included in pathophysiology of depression, then it can be supposed that effects of stress on the mechanisms of neuroplasticity contribute to the genesis of depression and long-term antidepressant treatment affects the same mechanisms (Pittenger \& Duman, 2008).

There are many evidences that antidepressants increase signalling pathways related to neuroplasticity by upregulation of cAMP/PKA/CREB cascade, by regulation of CaMKII activity and by upregulation of the MAPK cascade. The hypothesis that long-term antidepressant treatment enhances neuroplasticity is based on upregulation of expression of many neurotrophic factors, especially of BDNF, in the hippocampus and the prefrontal cortex (Bocchio-Chiavetto et al., 2006; Duman \& Monteggia, 2006; Nibuya et al., 1996; Pittenger \& Duman, 2008).

A neurotrophic model for the molecular mechanism of action of antidepressant treatments includes following steps: 1 . Antidepressant treatment causes direct inhibition of serotonin and/or norepinephrine reuptake or breakdown, which is followed by elevation of extracellular levels of serotonin and/or norepinephrine; 2. Long-term treatment causes adaptive changes in the function and expression of serotonin and norepinephrine receptors, increase in the cAMP signal transduction and increase in expression of the transcription factor CREB; 3. Increased activity of the cAMP signal transduction cascade induces increased expression of BDNF and its receptor trkB; thus, neuroplasticity is improved and neuron survival and recovery is increased.

The results support the hypothesis that treatment by antidepressant lead to effects similar to neurotrophic. One of the target genes of pharmacotherapy is BDNF gene. BDNF supports processes implicated in neuronal plasticity and in renewal or improvement of neuronal connectivity. The renewal of synaptic connections and signalling pathways enables the normal function of neurotransmitters. It is suggested, that antidepressants can eliminate stress effects on the hippocampus and improve the symptoms of depression in this way. Due to the complexity of intracellular processes it is relatively difficult to establish this 
hypothesis. There is not large longitudinal study that might prove the ability of antidepressants to reverse atrophy of brain structures and prevent it.

The chronic administration of antidepressants also increases neurogenesis in hippocampal structures, i.e. it increases proliferation and survival of new neurons. Reverse effects of stress and antidepressant on the hippocampal neurogenesis indicate that changes in hippocampal neurogenesis can be significant in clinic syndrome of depression, although it is a complex disorder that targets more than one region of the brain. Coupling of hippocampal neurogenesis to pathophysiology of depression requires further research to be confirmed (Gass \& Riva, 2007; Santarelli et al., 2003).

\subsubsection{Effect on inflammatory pathway}

Suggestion that the activation of immune responses and the release of inflammatory cytokines (including IL-1 $\beta$, IL-6, TNF- $\alpha$ ) may play a role in the pathophysiology of depression is supported by observation that there is association between antidepressant action and cytokine functioning. The most consistent finding has been that antidepressant treatment significantly reduces interleukin-6 (IL-6) plasma concentrations, which are elevated in depression (Janssen et al., 2010). Proposed mechanisms for the antidepressant effects on cytokine function include: 1. Increase of intracellular cAMP/PKA pathway by antidepressants leads to inhibition of NFKB, a transcription factor which promote proinflammatory gene expression; 2. Antidepressants and glucocorticoids may act via common intracellular signalling pathways; e.g. activated PKA is able to enhance glucocorticoid receptor-DNA binding (Pace \& Miller, 2009); 3. Increased extracellular levels of serotonin after treatment with serotonergic antidepressants exhibit immunosuppressive effects (Kubera et al., 2000), and depleted intracellular 5-HT levels reduce cytokine levels through inhibition of mRNA expression (Maes, 2001); 4. Antidepressants may reverse effect of cytokines on depression of hippocampal neurogenesis (Koo \& Duman, 2008). In conclusion, the inflammatory and neurodegenerative pathways might provide new targets for antidepressant development (Catena-Dell'Osso et al., 2011).

\subsubsection{Direct, early and long-term effects}

Sequence of biochemical events induced by antidepressants is crucial for discovery of molecular mechanisms associated with their therapeutic effects. Direct (immediate) biochemical effects of antidepressants leading to their therapeutic action include:

1. Inhibition of reuptake of monoamine neurotransmitters, i.e. inhibition of membrane transporters for serotonin, norepinephrine or dopamine.

2. Inhibition of metabolism of monoamine neurotransmitters, i.e. monoamine oxidase inhibition,

3. Receptor activation, e.g. postsynaptic serotonin receptors type $1 \mathrm{~A}\left(5-\mathrm{HT}_{1 \mathrm{~A}}\right)$ or sigma receptors.

4. Blockade (antagonism) of monoamine receptors, e.g. postsynaptic serotonin receptors type $2 \mathrm{~A}$ and $2 \mathrm{C}\left(5-\mathrm{HT}_{2 \mathrm{~A}}, 5-\mathrm{HT}_{2} \mathrm{C}\right)$ and presynaptic $\mathrm{a}_{2}$-adrenoceptors.

5. Inhibition or activation of several intracellular components of signalling pathways participant in neurotransmission. 
Neurochemical events for antidepressant action classified into direct (immediate) effects, early (intermediate) effects, and long-term (delayed) effects are summarized in Fig. 8.

\begin{tabular}{|c|c|c|}
\hline $\begin{array}{l}\text { Direct Effects: } \\
\text {-Inhibition of serotonin, norepinephrine } \\
\text { or dopamine transporters } \\
\text {-Monoamine oxidase inhibition } \\
\text {-Receptor activation }\left(5-\mathrm{HT}_{1 \mathrm{~A}}, \text { sigma) }\right. \\
\text {-Blockade of receptors }\left(\mathrm{a}_{2}-\mathrm{AR}, 5-\right. \\
\left.\mathrm{HT}_{2 \mathrm{~A}}, 5-\mathrm{HT}_{2 \mathrm{C}}, \mathrm{NMDA}\right) \\
\text {-Intracellular action }\end{array}$ & $\begin{array}{l}\text { Early Effects: } \\
\text {-Increasing of availability and } \\
\text { extracellular levels of monoamine } \\
\text { neurotransmitters } \\
\text {-Increasing of monoamine receptors } \\
\text { activation } \\
\text {-Activation of intracellular signalling } \\
\text { pathways (adenylate cyclase, } \\
\text { phosphoinositide, calcium) } \\
\text {-Activation of transcription factors } \\
\text { (CREB, AP-1, etc.) } \\
\text {-Increasing of gene expression of } \\
\text { neurotrophic factors (BDNF, NGF, } \\
\text { etc.) } \\
\text {-Activation of neurotrophic signalling } \\
\text { pathway } \\
\text {-Feedback effects on } \\
\text { neurotransmission }\end{array}$ & $\begin{array}{l}\text { Long-term Effects: } \\
\text {-Receptor adaptation (desensitisation } \\
\text { or down-regulation; sensitization or } \\
\text { up-regulation) } \\
\text { - Increasing of structural plasticity } \\
\text { (synaptogenesis; formation or } \\
\text { changes of axons, synapses, } \\
\text { dendrites (branching, sprouting) and } \\
\text { dendritic spines) and functional } \\
\text { plasticity (LTP, LTD, strength of } \\
\text { synapse) } \\
\text {-Antiapoptotic effects } \\
\text {-Support of neurogenesis, cellular } \\
\text { resilience and neuron survival } \\
\text {-Anti-inflammatory effects } \\
\text {-HPA axis regulation } \\
\text {-Protection against neurotoxic effects } \\
\text { of cellular stress } \\
\text {-Synchronization of biological rhythms } \\
\text {-Epigenetic changes }\end{array}$ \\
\hline
\end{tabular}

Fig. 8. Sequence of effects of antidepressants

Immediate biochemical effects of antidepressants are followed by early events, such as increasing of availability and extracellular levels of monoamine neurotransmitters, increasing of monoamine receptors activation, activation of intracellular signalling pathways, activation of transcription factors and increasing of gene expression of neurotrophic factors.

It is evident that adaptive changes in central neurotransmission are responsible for therapeutic effects of antidepressants. These adaptive processes and their regulatory mechanisms are studied on the neurochemical, neuroimmune, neuroendocrine, chronobiological, and genetic level primarily:

1. Neurochemical events include a) changes of neurotransmitter receptor density and sensitivity, which were not confirmed for in vivo treatment with many antidepressants and mood stabilizers on patients with affective disorders (Nikolaus et al., 2009; Richelson, 2003); b) antiapoptotic effects and changes in gene expression, neuroplasticity and neurogenesis, when stress-induced or depression-induced damage of brain cell functions and their interconnections are recovered after long-term treatment with antidepressants (Duman, 2009).

2. Neuroimmune approach is based on observations that a) major depressive disorder is an inflammatory disorder with an overproduction of proinflammatory cytokines (Maes et al., 2009); b) anti-inflammatory effects of antidepressants participate on their pharmacological effects (Janssen et al., 2010).

3. Neuroendocrine hypotheses suppose that therapeutic effects of antidepressants consist in regulation of HPA axis, which can be overactivated during depression (Nikisch, 2009).

4. Chronobiological hypotheses connect therapeutic effects of antidepressants with synchronization of biological rhythms disturbed in depression (Bunney \& Potkin, 2008; Mendlewicz, 2009; Schulz \& Steimer, 2009). 
5. Genetic factors contribute for about $50 \%$ of the antidepressant response (Crisafulli et al., 2011). Epigenetic changes are studied both in relation to gene-environment interactions (G × E) (Caspi et al., 2003; Uher, 2008) and in animal models of stress, depression and antidepressant treatment (Schroeder et al., 2007; Tsankova et al., 2007; Yasuda et al., 2009).

\subsection{Mood stabilizers}

Mood stabilizers are psychiatric medication used in treatment of mood disorders, which are characterized by intense and sustained mood shifts (e.g. bipolar disorder). Most of mood stabilizers are anticonvulsants (valproate, carbamazepine, and lamotrigine), with an important exception of lithium, which is the oldest and the best known mood stabilizing drug. Some atypical antipsychotics (olanzapine, quetiapine, aripiprazole, risperidone, ziprasidone) have mood stabilizing effects, as well. It is also suggested that $\omega-3$ fatty acids may have a mood stabilizing effect. It is hypothesized that $\omega-3$ fatty acid deficiency may contribute to elevated phosphoinositide-PKC in neuropsychiatric illness (schizophrenia, bipolar disorder, major depressive disorder), because $\omega-3$ fatty acids act as endogenous inhibitors of second messenger-regulated protein kinases (PKA, PKC, CaMK, MAPK) (McNamara et al., 2006; Mirnikjoo et al., 2001).

Mood stabilizers affect multiple sites in intracellular signalling pathways (Fig. 9). Main targets of mood stabilizers are neurotrophin BDNF, ERK pathway, and pathways modulated by GSK-3 or Bcl-2 (Einat \& Manji, 2006; Gould \& Manji, 2005; Shaltiel et al., 2007). Molecular and cellular targets of mood stabilizers include enzymes inhibited by lithium (inositol monophosphatase, inositol polyphosphate 1-phosphatase, GSK-3, fructose 1,6-bisphosphatase, bisphosphate nucleotidase, phosphoglucomutase), enzymes inhibited by valproate (succinate semialdehyde dehydrogenase, succinate semialdehyde reductase, histone deacetylase), targets of carbamazepine (sodium channels, adenosine receptors, adenylate cyclase), and components of signalling pathways regulated by multiple drugs (PKC, cAMP, arachidonic acid) (Gould et al., 2004). Furthermore, lithium and valproate reduce transport of myo-inositol into the cells, which leads to reduced PKC activity. Lithium and valproate increase Bcl-2 concentrations (Chen et al., 1999) and inhibit GSK-3 activity (lithium directly, valproate indirectly). Valproate activates MAPK signalling pathway and regulates stress proteins of endoplasmic reticulum (Bown et al., 2002). Through the effects on Bcl-2 and p53 (proapoptotic protein), lithium affects mitochondria by stabilization of membrane integrity and prevention of mitochondrial membrane permeability transition pores (MPTPs) opening; i.e. by regulating the key process in cell death leading to at least temporary loss of $\Delta \psi_{\mathrm{m}}$, input of water into matrix and equilibration of ions concentrations.

Both lithium and valproate have neuroprotective effects based on protection from glutamatergic neurotoxicity by inactivation of NMDA receptors, on activation of cell survival factors such as phosphoinositide 3-kinase/protein kinase B pathway, and on induction of neurotrophic and neuroprotective proteins. Lithium protects against DNA damage, caspases activation, and apoptosis of neurons (Chuang, 2005). Increased concentrations of $\mathrm{N}$-acetyl aspartate (NAA, marker of neuronal viability and functionality) in grey matter after the chronic lithium administration support its strong neuroprotective and neurotrophic effects in humans. Lithium also increases hippocampal neurogenesis. 


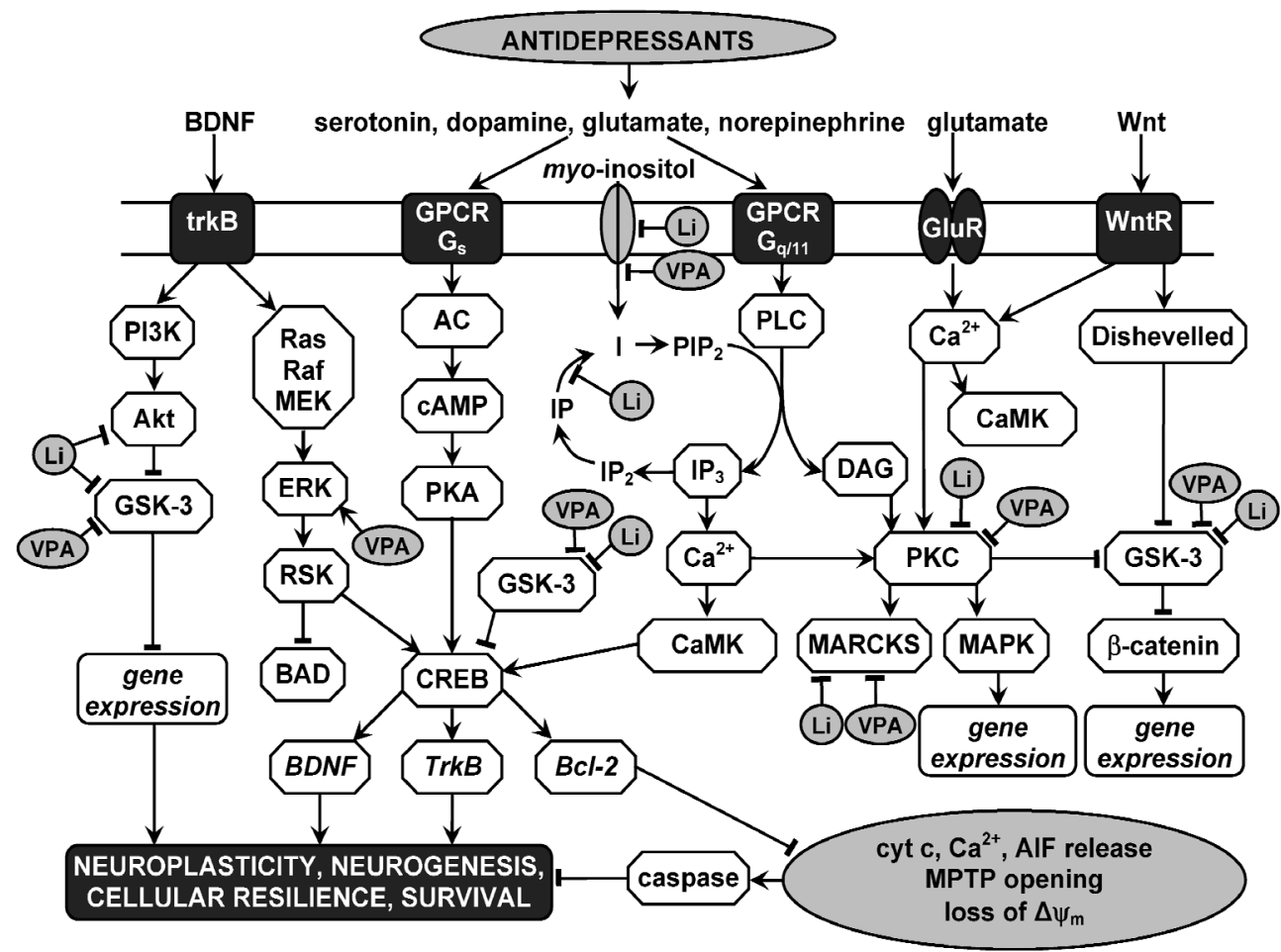

AC - adenylate cyclase (adenylyl cyclase); Akt - protein kinase B (PKB); BAD - proapoptotic factor (Bcl2-associated death promoter); Bcl-2 - antiapoptotic factor of Bcl-2 (B-cell CLL/lymphoma 2) family; BDNF - brain-derived neurotrophic factor; CaM - calmodulin; CaMK - calcium and calmodulindependent protein kinase; cAMP - cyclic adenosine monophosphate; CREB protein - cAMP response element-binding protein; DAG - diacylglycerol; ERK - extracellular signal-regulated kinase; GluR ionotropic glutamate receptor; GPCR - G protein-coupled receptors; GSK-3 - glycogen synthase kinase3; I - inositol; IP - inositol monophosphate; $\mathrm{IP}_{2}$ - inositol bisphosphate; $\mathrm{IP}_{3}$ - inositol trisphosphate; MAPK - mitogen-activated protein kinase; MARCKS - myristoylated alanine-rich C-kinase substrate; MEK - mitogen-activated protein kinase kinase; MPTP - mitochondrial membrane permeability transition pore; PI3K - phosphoinositide 3-kinase; $\mathrm{PIP}_{2}$ - phosphatidylinositol 4,5-bisphosphate; PKA protein kinase A; PKC - protein kinase C; PLC - phosphoinositide phospholipase C; Raf - protein kinase ; Ras - small GTPase; RSK - ribosomal protein S6 kinase; trkB - neurotrophic tyrosine kinase, receptor, type 2; VPA - valproic acid; WntR - Wnt receptor (transmembrane receptor of the Frizzled family); $\longrightarrow$ - activation; $\longrightarrow$ - inhibition

Fig. 9. Neurotrophic and neuroprotective effects of antidepressants and mood stabilizers. Detailed description in the text.

\section{Advances in neurochemical hypotheses of mood disorders}

There are many hypotheses of mood disorders; however, current clinical, neurochemical, neurophysiological, genetic, and neuroimaging data are not sufficient for enunciation of theory of mood disorder. Thus, the ethiopathogenesis of major depressive disorder and other mood disorders is still unclear. 
The neurochemical hypotheses of mood disorders were developed from neurotransmitter hypotheses to receptor and postreceptor hypotheses. Inadvertently induced depression by reserpine and effectiveness of first antidepressants from the class of TCA or MAOI led to the hypothesis that affective disorders are due to catecholamine and/or indolamine deficiency in the CNS (Coppen, 1967; Schildkraut, 1965). Single deficit of monoaminergic neurotransmission is insufficient to elucidation of neurochemistry of mood disorders. It was deduced that disposition of CNS characterized by disturbance in function of receptors for the key monoamine neurotransmitters is determining factor. Receptor malfunction may be caused by depletion of monoamine neurotransmitters, by abnormalities in the receptor density and sensitivity, or by problems with signal transduction on postreceptor level. It was formulated a large amount of receptor hypotheses. Classical norepinephrine receptor hypothesis of affective disorders supposed increased density of postsynaptic $\beta$-AR in depression (Banerjee et al., 1977; Vetulani \& Sulser, 1975). Very elegant, although unconfirmed, was receptor catecholamine hypothesis (Richelson, 1990) that supposes that supersensitivity of catecholamine receptors in the presence of low levels of serotonin is the biochemical basis of depression. According to receptor hypotheses the common final result of chronic treatment by majority of antidepressants is the down-regulation or up-regulation of postsynaptic or presynaptic receptors. The delay of clinical response corresponds with these receptor alterations. However, problems in interpretation of molecular mechanisms of action of mood stabilizers and the introduction of new, more selective antidepressants led to new reflection upon the mechanisms of their action and to new neurochemical hypotheses. The most promising are recent investigations of the signalling pathways ensuring signal transduction.

Introduction of newer antidepressants sustained the monoamine deficiency hypothesis and the monoaminergic signalling pathways continues to be one of the key targets of new antidepressants. For decades, research focused mainly on the role of monoamines in mood disorders. However, data are inconclusive and the monoamine hypothesis seems to be insufficient to explain depression (Catena-Dell'Osso et al., 2011). E.g., in vivo neuroimaging studies on human brain neurotransmission provide little evidence about deficits in monoaminergic neurotransmission. Reports on positron emission tomography (PET) or single-photon emission computed tomography (SPECT) of neurotransmission in depressive disorders showed that there is usually no reliable relationship between the binding potential of the neuroreceptor or transporter and the clinical condition of depressed subject (Nikolaus et al., 2009; Smith \& Jakobsen, 2009).

While dysfunctions within monoaminergic neurotransmitter systems are likely to play an important role in pathophysiology of mood disorders, it probably represents the downstream effects of more primary abnormalities in signal transduction. Thus, new theories about the pathophysiology of depression and the action of antidepressant treatment proposes that mood disorders are caused by structural or functional changes in particular molecules and signalling pathways in the brain, and that antidepressants function by counteracting these molecular changes. Neurodegeneration or impaired neurogenesis may be important mechanism of depression, and neurotrophins are key regulators of neurogenesis and neuroplasticity. Recovery of brain networks through increase of neuroplasticity induces antidepressant effect. It is supposed that structural and functional brain abnormalities in patients with depressive disorder may be associated with low levels of BDNF, abnormal function of hypothalamicpituitary-adrenal (HPA) axis and glutamatergic toxicity (aan het Rot et al., 2009; Krishnan \& Nestler, 2008; Mathew et al., 2008). 
Research on the biological basis of mood disorders emphasises the changes of neural networks and synaptic plasticity. Evidence exists for impairment of neuroplasticity in major depression. Chronic stress is known to contribute both to development of major depression in vulnerable persons and to reduction of synaptic plasticity, induction of structural changes in dendrites, and impairment of neurogenesis (Pittenger \& Duman, 2008). Mitochondria may be primary regulators of these processes, as they regulate not only neuronal survival and death, but also plasticity. There is a mounting evidence for the role of mitochondrial dysfunction in the pathophysiology and treatment of bipolar disorder (Quiroz et al., 2008). Attention is paid also to changes in inflammatory pathways, because monoaminergic systems, cellular energetics and inflammation are interrelated in many complex manners (Gardner \& Boles, 2011).

\subsection{Monoamine hypothesis}

Classic monoamine hypothesis of depression proposed that depression might be produced by a serotonin or norepinephrine deficiency at functionally important receptor sites in the brain, i.e. that brain monoamine systems have a primary direct role in depression. Nevertheless, the monoamine hypothesis of depression in itself could neither explain the whole mechanism of action of antidepressants, nor could it provide an explanation for how monoamine loss occurs (Nestler et al., 2002). According to advanced monoamine theory (Meyer et al., 2006), serotonin or norepinephrine levels in the brain are regulated by monoamine oxidase type A (MAO-A) activity mainly, and severity of symptoms of depression is related to changes in the activity of monoamine transporters in specific brain regions. Thus, both MAO-A activity and density of transporters are included in the pathophysiology of affective disorders. The advanced monoamine hypothesis was supported by observation that during a major depressive episode, both MAO-A density is elevated, resulting in greater metabolism of monoamines in the brain (Meyer et al., 2009), and brain SERT binding is diminished (Selvaraj et al., 2011).

In order to test monoamine hypothesis, a series of studies was conducted to evaluate effects of monoamine depletion on depressive symptoms in depressed patients and in healthy controls. Relapse after serotonin depletion or catecholamine depletion was found to be specific to the type of antidepressant treatment and type of depletion. Serotonin or norepinephrine/dopamine depletion did not decrease mood in healthy controls and slightly lowered mood in healthy controls with a family history of major depressive disorder. In drug-free patients with major depressive disorder in remission, a moderate mood decrease was found for acute tryptophan depletion only. However, acute tryptophan depletion induced relapse in patients in remission who used serotonergic antidepressants (Delgado et al., 1999). Depletion studies failed to demonstrate a causal relation between serotonin and norepinephrine with depressive disorder (Cowen, 2008; Ruhé et al., 2007). The effects of acute tryptophan depletion on cognition in non-vulnerable participants are independent of mood changes (Mendelsohn et al., 2009). Even simultaneous disruption of serotonin and catecholamine systems didn't significantly alter mood in unmedicated depressed subjects (Berman et al., 2002). These findings forced a major revision of the classic monoamine hypothesis of depression. According to this revised monoamine theory of depression (aan het Rot et al., 2009; Heninger et al., 1996) monoamine systems are only modulating other brain neurobiological systems that have more primary role in depression. 


\subsection{Neurotrophic, neuroplasticity and neurogenesis hypotheses}

The neurotrophic hypothesis of depression (Duman et al., 1997; Duman, 2002; Zarate et al., 2006a; Einat \& Manji, 2006) supposed that vulnerability to depression can arise as a result of neuronal damage (Table 1), e.g. after chronic stress, long-term increased levels of glucocorticoids, hypoglycemia, ischemia, certain viral infections, effects of neurotoxins, etc. The therapeutic effects of antidepressants consist of increased function of the noradrenergic or serotonergic system. It leads to increased activity of transcription factor CREB, higher expression of neurotrophin BDNF and its receptor trkB, and consequently to increased neuronal plasticity and resumption of cellular functions.

\begin{tabular}{ll}
\hline Stimuli & Mechanisms \\
\hline Chronic stress & Disturbed energetic metabolism \\
Hypoglycemia & Lack of growth factors \\
Ischemia & Excitotoxicity \\
Neurotoxins & Oxidative stress \\
Viral infections & Necrotic and apoptotic processes \\
Y-radiation, UV & Inflammatory processes \\
\hline
\end{tabular}

Table 1. Stimuli and mechanisms of neuron damage, which could be related to vulnerability to depression

Series of studies support the hypothesis that a reduction of BDNF could contribute to depression and that antidepressants mediate their therapeutic benefit by increasing levels of this factor in the hippocampus. A polymorphism in the BDNF gene has been associated with depression and bipolar disorder. BDNF levels have been found to be reduced in postmortem brain samples and in the blood of depressed patients, and these reductions are reversible by successful antidepressant treatment (Castrén et al., 2007; Castrén \& Rantamäki, 2008). In addition, the regulation of other growth factors may also play a role in the pathophysiology and the treatment of depression (Duman \& Monteggia, 2006). Stress produces a sustained suppression of BDNF transcription through histone methylation, whereas antidepressants restore BDNF synthesis through histone acetylation (Tsankova et al., 2006). This suggests that chronic stress can cause long-lasting epigenetic changes that might be related to increased vulnerability to depression.

Local infusions of BDNF into specific brain regions showed to mimic antidepressant effects in behavioural models of depression. However, the loss of BDNF and signalling through the trkB receptor in broad forebrain regions per se is not sufficient to mediate depression-like behaviour (Duman \& Monteggia, 2006). BDNF does not produce uniform effects throughout the brain. Infusion of BDNF into the ventral tegmental area might be related to the development of a depression-like phenotype; therefore, the role of BDNF in the ventral tegmental area - nucleus accumbens (VTA-NAc) pathway is opposite to the role of BDNF in the hippocampus (Eisch et al., 2003). It is hypothesized that BDNF signalling in the VTANAc is required for the establishment of associations with negative emotional stimuli; and under pathological conditions this signalling may establish abnormal associations leading to certain symptoms of depression (Nestler \& Carlezon, 2006).

The neurogenesis (neurogenic) hypothesis of depression (Jacobs, 2002) proposes that depression may develop due to the decreased neurogenesis in hippocampus and 
antidepressants takes effect through the stimulation of neurogenesis. The first component of this hypothesis is not tenable, and the evidence for second component is conflicting (Sapolsky, 2004).

Behavioural data support the hypothesis that regulation of neuronal plasticity might play an important role in expression of symptoms of bipolar disorder. Major intracellular signalling pathways in bipolar disorder and neural plasticity include protein kinase C (PKC) and extracellular signal regulated kinase (ERK) cascades, glucocorticoid receptor modulation, glycogen synthase kinase-3 (GSK-3), and antiapoptotic Bcl-2 (B-cell CLL/lymphoma 2), AMPA (a-amino-3-hydroxyl-5-methyl-4-isoxazole propionic acid) receptors, and inositol homeostasis (Einat \& Manji, 2006). The neuroplasticity hypothesis of depressive disorder (Pittenger \& Duman, 2008) suggests that impaired mechanisms of neuroplasticity are core pathophysiological feature of the disorder, where chronic stress is an important causal factor in the development of this impairment, and where long-term treatment with antidepressants leads to modulation of impaired mechanisms of neuroplasticity. However, alterations in neuroplasticity do not produce the same effects in different brain regions.

Hypothesis of cellular plasticity (Kempermann \& Kronenberg, 2003) relates the neurotrophic and the neurogenic hypothesis in the statement that depression can be generally caused by damaged cellular plasticity leading to inadequate relations between structure and function.

Molecular mechanisms leading to a disturbance of neuroplasticity are not known sufficiently. The bioenergetic and neurochemical model of bipolar disorder attempts to identify these mechanisms and focuses attention on mitochondrial dysfunctions (Kato \& Kato, 2000; Stork \& Renshaw, 2005).

\subsection{Network hypothesis}

According to the network hypothesis of depression, changes in levels of neurotrophins may not directly produce depression or an antidepressant effect, but neurotrophins may act as critical tools in the process whereby environmental conditions guide neuronal networks to better adapt to the environment (Castrén \& Rantamäki, 2010).

The network hypothesis (Castrén, 2005) proposes that mood disorders reflect problems in information processing within particular neural networks in the brain; antidepressant drugs and other treatments, which alleviate depression, function by gradually improving information processing within these networks. Therefore, disorders of the nervous system, including depression, might represent disturbances in the activity-dependent information processing of the brain, rather than in the chemical balance of signalling molecules. However, some observations seem to be incompatible with the network hypothesis, e.g. rapid relapse of depressive symptoms in some patients, circadian variations in mood, and the effect of sleep deprivation on improvement of the mood of patients with depression. These rapid effects on mood can not be accounted for a gradual change in the structure of mood influencing neural networks.

The network hypothesis emphasizes the importance of processing of environmental information (such as social communication) in the recovery of the brain functions during treatment of mood disorders; so, treatment with psychotropic drug in itself is insufficient. 
Findings that psychotherapy result in detectable changes in the brain (Etkin et al., 2005) and that combined use of psychotherapy and medication can lead to better treatment outcomes than the use of either mode of therapy alone (Elkin et al., 1989) are consistent with the network hypothesis.

\subsection{Inflammatory and neurodegenerative hypothesis}

The central nervous system, endocrine and immune systems use neurotransmitters, cytokines and hormones to communicate among them (Haddad et al., 2002). Now there is evidence that the activation of the immune system is associated with the symptoms of depression (Leonard \& Myint, 2009; Catena-Dell'Osso et al., 2011). The inflammatory and neurodegenerative hypothesis of depression (Maes et al., 2009) supposes that depression is associated with both inflammatory processes, as well as with neurodegeneration and reduced neurogenesis. According to this hypothesis, enhanced neurodegeneration and impaired neurogenesis in depression are caused by inflammatory processes, related to the production of oxidative and nitrosative stress, tryptophan catabolites along the indoleamine-2,3-dioxygenase pathway, proinflammatory cytokines and lowered $\omega-3$ polyunsaturated fatty acid status. Anti-inflammatory compounds should be able to counteract at least partly the enhanced neurodegeneration and decreased neurogenesis.

\subsection{Mitochondrial dysfunction hypothesis}

While dysfunctions within monoaminergic neurotransmitter systems are likely to play an important role in pathophysiology of mood disorders, it probably represents the downstream effects of more primary abnormalities in signal transduction. New theories about the pathophysiology of depression and mechanisms of action of antidepressants proposes that regulation of intracellular signalling pathways manifested by disturbed neuroplasticity plays a critical role in higher-order brain functions. Mitochondria may be primary regulators of these processes. It is supposed that mitochondrial dysfunctions are included in pathophysiology of mood disorders. Disturbances in activity of mitochondrial enzymes, effects of intracellular calcium and energy metabolism, damage of mitochondrial DNA, and action of psychotropics on mitochondria were observed in many neuropsychiatric illnesses, mood disorders included.

Subtle deficits in mitochondrial function likely play an important role in various aspects of bipolar disorder, and enhancing mitochondrial function may represent a critical component for the treatment of the disorder (Quiroz et al., 2008). Changes in cerebral concentrations of $\mathrm{N}$-acetyl aspartate (NAA), glutamate/glutamine, choline-containing compounds, myoinositol, lactate, phosphocreatine, phosphomonoesters, and intracellular $\mathrm{pH}$ in bipolar subjects were described (Yildiz-Yesiloglu \& Ankerst, 2006). A hypothesis of mitochondrial dysfunction in bipolar disorder (Stork \& Renshaw, 2005) was proposed and involved impaired oxidative phosphorylation, a resultant shift toward glycolytic energy production, a decrease in total energy production (decreased ATP production) and/or substrate availability, and changed concentrations of phosphomonoesters and altered phospholipid metabolism.

Neuronal calcium homeostasis and calcium signalling regulate multiple neuronal functions, including synaptic transmission, neuronal plasticity and survival. The idea that altered 
intracellular calcium signalling may be crucial for the molecular mechanisms leading to both schizophrenia and affective disorders was firstly suggested by Jimerson et al. (1979). Recently, disturbed calcium homeostasis has been studied in neurodegenerative (Wojda et al., 2008) and mood disorders. Mitochondrial DNA (mtDNA) mutations in the brain, associations of mtDNA polymorphisms and bipolar disorder and changes in gene expression related to mitochondria in the brain were observed (Kato, 2008). Calcium and mitochondrial dysfunction hypothesis of bipolar disorder offers that mtDNA polymorphisms/mutations or mtRNA deletions caused by nuclear gene mutations can cause mitochondrial dysregulation of calcium leading to symptoms of bipolar disorder (Kato \& Kato, 2000; Kato, 2007, 2008).

Mitochondrial hypothesis of bipolar affective disorder corresponds both to the neurotrophic and neuroplasticity hypothesis and to the inflammatory and neurodegenerative hypothesis because of an important role of mitochondria in cell energetic, regulation of calcium signalling pathway, production of reactive oxygen species and apoptosis, i.e. in processes determining synaptic plasticity, damage, repairing, survival or death of neurons.

\section{Conclusion}

The understanding of signalling pathways and their interconnections on the intracellular level is necessary to understand normal and damaged functions of the CNS. The exact neurochemical processes included in mood disorders have not yet been sufficiently explored; the main attention has been focused on changes in monoaminergic neurotransmitter systems and neuroplasticity. It is suggested that the changes in cognitive functions, learning, memory and the emotions during depression are caused by damaged neuroplasticity in hippocampus, amygdala and cerebral cortex. Changes in effects of neurotransmitters, hormones and growth factors probably cause changes of neuroplasticity; processes leading to changed neuroplasticity can be initiated by mitochondrial dysfunctions.

The long-term administration of antidepressants leads to the effects similar to neurotrophic, as seen through the activation of transcription factors and increased gene expression of neurotrophins. Mood stabilizers, such as lithium and valproate, strongly activate also neurotrophic signal cascades and affect other signalling pathways. Intracellular processes among activation of receptor and increased gene expression of neurotrophins and other molecules have not yet been sufficiently clarified. Variability in these intracellular processes participates probably on interindividual differences of the response to treatment with antidepressant or in drug resistance.

On the basis of clinical analyses and findings about signalling pathway components affected by administration of psychotropic drugs, studies of following components seem to be perspective: neurotransmitter receptors and transporters (especially for serotonin and norepinephrine), monoamine oxidases, adenylate cyclase and phosphoinositide cascade and MAPK pathway, mitochondrial dysfunctions, reactive oxygen species, nitric oxide and cytoplasmic calcium. The role of membrane potential and membrane lipids in the proper function of neuronal membranes should not be forgotten.

Signal transduction is an amount of processes by which a cell converts one kind of signal into another. Neuronal signal transduction pathways involve neurotransmitter release, receptor activation and ordered sequence of biochemical reactions inside the cell. These 
processes can be rapid in the case of ion-channels opening (milliseconds), slower in the case of the activation of second messenger systems (minutes), and slow in the case of gene expression (hours, and even days). As signal propagates from a relatively small initial stimulus to a final large response, the signal cascade involves increasing number of proteins and other molecules (Fišar \& Hroudová, 2010). Many feedbacks and cross reactions are included in this amplification of the signal. Determining factors in signal transduction are input signals and concentration, activity and subcellular localization of participating molecules. All these factors are determined by previous history of the brain, and it is probable that participate in interindividual differences in response to the same stimuli.

Regulation of critical intracellular signalling pathways plays a critical role in higher-order brain functions, which are altered in mood disorders, suggesting the involvement of dysfunctions of signalling pathways in the pathophysiology and the treatment of mood disorders (Gould et al., 2007). It can be concluded that both some structural deviations in neural networks and disturbances of signal transduction in certain neurons participate in development of mood disorders. It is assumed that novel biomarkers of mood disorders and/or predictors of efficiency of pharmacotherapy may be discovered on the basis of this research.

It is suggested that environmental stress and genetic risk variants interact with each other in a complex manner to alter neural circuitry and evoke illness. Considering the existence of very rapid distinct shifts of mood (e.g. ultra-ultra-rapid cycling in bipolar affective disorder) (Kramlinger \& Post, 1996), developmental and structural changes in neural networks could be considered as necessary condition for vulnerability to the development of pathological states of mood, whereas disturbances in signal transduction pathways in chemical synapses could be related to the onset of specific symptoms of mood disorder. Distinct shifts in mood and activity occur both in "normal" and "disordered" man and can be induced both by endogenous and external stimuli. Therefore, occurrence of several symptoms, their severity and time duration depend on the proportion of dysfunction of brain homeostatic mechanisms in various brain areas. It may be supposed that both normal and pathological shifts of mood (e.g. ultradian cycling or rapid switching from episode of depression to mania) are associated with changes in expression or activity of specific compounds of signal transduction pathways related to monoaminergic and glutamatergic systems. Identification of compounds of signal transduction that are primarily responsible for shifts of mood remains incomplete. We suppose that mild dysfunction of some mitochondrial functions might be basis for homeostatic imbalance in synapses during episodes of depression, hypomania, mania or the appearance of mixed states.

Identification of biomarkers of mood disorders and factors capable of predicting the response to treatment with antidepressants has not been sufficiently successful (Balon, 1989; Joyce \& Paykel, 1989; Fišar \& Raboch, 2008). In accordance to actual neurochemical hypotheses of mood disorders, biological markers have been primarily found at the level of neurotransmitter concentrations, their metabolites or precursors. Subsequently, attention was shifted to the receptor systems, and since the 1990's, intracellular processes have become of primary interest. There is evidence that growth factors, proinflammatory cytokines, endocrine factors, and metabolic markers contribute to the pathophysiology of major depressive disorder (Schmidt et al., 2011). The chance to find sensitive and specific biological predictors of antidepressant treatment has been increased, because of the 
introduction of new molecular biology methods. These methods enable better observation of cellular processes connected with the transduction of nervous signals in the brain. The choice of parameters, which should be studied as perspective biological markers of mood disorders, has been derived first of all from new findings of signalling pathways involved in neurotransmission and from above mentioned neurochemical hypotheses of mood disorders. Following parameters could play a principal role in findings of biological markers of mood disorders: energetic metabolism and mitochondrial dysfunctions, activities of protein kinases, transcription factors, neurotrophins, proapoptotic and antiapoptotic factors, caspases, polyunsaturated fatty acids, membrane potential and fluidity, cortisol, melatonin, homocysteine, cytokines, SERT, $\mathrm{Na}^{+} \mathrm{K}^{+}$-ATPases, ROS, NO, cytoplasmic $\mathrm{Ca}^{2+}$ and $\mathrm{CaM}$, enzymes GSK-3, COMT, MAO and cytochrome P450. According to the complexity and connectivity of signalling pathways involved in ethiopathogenesis of mood disorders, number of chosen parameters is not final.

\section{Acknowledgment}

This work was supported by a Research project MSM0021620849 given by Ministry of Education, Youth and Sports of the Czech Republic and by grant No 41310 given by Grant Agency of Charles University.

\section{References}

aan het Rot, M., Mathew, SJ. \& Charney DS. (2009). Neurobiological mechanisms in major depressive disorder. CMAJ, Vol. 180, No. 3, pp. 305-313

Abitz, M., Nielsen, RD., Jones, EG., Laursen, H., Graem, N. \& Pakkenberg, B. (2007). Excess of neurons in the human newborn mediodorsal thalamus compared with that of the adult. Cereb. Cortex, Vol. 17, No. 11, pp. 2573-2578

Abraham, WC. \& Bear, MF. (1996). Metaplasticity: the plasticity of synaptic plasticity. Trends Neurosci., Vol. 19, No. 4, pp. 126-130

Aguilera, M., Arias, B., Wichers, M., Barrantes-Vidal, N., Moya, J., Villa, H., van Os, J., Ibáñez, MI., Ruipérez, MA., Ortet, G. \& Fañanás L. (2009). Early adversity and 5HTT/BDNF genes: new evidence of gene-environment interactions on depressive symptoms in a general population. Psychol. Med., Vol. 39, No. 9, pp. 1425-1432

Atlante, A., Calissano, P., Bobba, A., Giannattasio, S., Marra, E. \& Passarella, S. (2001). Glutamate neurotoxicity, oxidative stress and mitochondria. FEBS Lett., Vol. 497, No. 1, pp. 1-5

Bach, AWJ., Lan, NC., Johnson, DL., Abell, CW., Bembenek, ME., Kwan, S-W., Seeburg, PH. \& Shih, JC. (1988). cDNA cloning of human liver monoamine oxidase A and B: molecular basis of differences in enzymatic properties. Proc. Natl. Acad. Sci. USA, Vol. 85, No. 13, pp. 4934-4938

Balon, R. (1989). Biological predictors of antidepressant treatment outcome. Clin. Neuropharmacol., Vol. 12, pp. 195-214

Banerjee, SP., Kung, LS., Riggi, SJ. \& Chanda, SK. (1977). Development of $\beta$-adrenergic receptor subsensitivity by antidepressants. Nature, Vol. 268, pp. 455-456

Battaini, F. (2001). Protein kinase C isoforms as therapeutic targets in nervous system disease states. Pharmacol. Res., Vol. 44, pp. 353-361 
Berman, RM., Sanacora, G., Anand, A., Roach, LM., Fasula, MK., Finkelstein, CO., Wachen, RM., Oren, DA., Heninger, GR. \& Charney, DS. (2002). Monoamine depletion in unmedicated depressed subjects. Biol. Psychiatry, Vol. 51, No. 6, pp. 469-473

Berridge, MJ., Lipp, P., Bootman, MD. (2000). The versatility and universality of calcium signalling. Nat. Rev. Mol. Cell Biol., Vol. 1, pp. 11-21

Blendy, JA. (2006). The role of CREB in depression and antidepressant treatment. Biol. Psychiatry, Vol. 59, pp. 1144-1150

Bocchio-Chiavetto, L., Zanardini, R., Bortolomasi, M., Abate, M., Segala, M., Giacopuzzi, M., Riva, M. A., Marchina, E., Pasqualetti, P., Perez, J. \& Gennarelli, M. (2006). Electroconvulsive Therapy (ECT) increases serum Brain Derived Neurotrophic Factor (BDNF) in drug resistant depressed patients. Eur. Neuropsychopharmacol., Vol. 16, pp. 620-624

Bown, CD., Wang, JF., Chen, B. \& Young, LT. (2002). Regulation of ER stress proteins by valproate: therapeutic implications. Bipolar Disord., Vol. 4, pp. 145-151

Brown GC. (2010). Nitric oxide and neuronal death. Nitric Oxide, Vol. 23, No. 3, pp. 153-165

Bunney JN. \& Potkin SG. (2008). Circadian abnormalities, molecular clock genes and chronobiological treatments in depression. Br. Med. Bull., Vol. 86, pp. 23-32

Carlezon, WAJr., Duman, RS. \& Nestler, EJ. (2005). The many faces of CREB. Trends Neurosci., Vol. 28, No. 8, pp. 436-445

Caspi, A., Sugden, K., Moffitt, TE., Taylor, A., Craig, IW., Harrington, H., McClay, J., Mill, J., Martin, J., Braithwaite, A. \& Poulton R. (2003). Influence of life stress on depression: moderation by a polymorphism in the 5-HTT gene. Science, Vol. 301, No. 5631, pp. 386-389

Castrén, E. (2005). Is mood chemistry? Nat. Rev. Neurosci., Vol. 6, No. 3, pp. 241-246

Castrén, E., Võikar, V. \& Rantamäki, T. (2007). Role of neurotrophic factors in depression. Curr. Opin. Pharmacol., Vol. 7, No. 1, pp. 18-21

Castrén, E. \& Rantamäki, T. (2008). Neurotrophins in depression and antidepressant effects. Novartis Found. Symp., Vol. 289, pp. 43-52

Castrén, E. \& Rantamäki, T. (2010). Role of brain-derived neurotrophic factor in the aetiology of depression: implications for pharmacological treatment. CNS Drugs, Vol. 24, No. 1, pp. 1-7

Catena-Dell'Osso, M., Bellantuono, C., Consoli, G., Baroni, S., Rotella, F. \& Marazziti, D. (2011). Inflammatory and neurodegenerative pathways in depression: a new avenue for antidepressant development? Curr. Med. Chem., Vol. 18, No. 2, pp. 245255

Chen, AC., Shirayama, Y., Shin, KH., Neve, RL. \& Duman, RS. (2001). Expression of the cAMP response element binding protein (CREB) in hippocampus produces an antidepressant effect. Biol. Psychiatry, Vol. 49, No. 9, pp. 753-762

Chen, G., Zeng, WZ., Yuan, PX., Huang, LD., Jiang, YM., Zhao, ZH. \& Manji, HK. (1999). The mood-stabilizing agents lithium and valproate robustly increase the levels of the neuroprotective protein bcl-2 in the CNS. J. Neurochem., Vol. 72, pp. 879-882

Chevaleyre, V., Takahashi, KA. \& Castillo, PE. (2006). Endocannabinoid-mediated synaptic plasticity in the CNS. Annu. Rev. Neurosci., Vol. 29, pp. 37-76

Chiavegatto, S. \& Nelson, RJ. (2003). Interaction of nitric oxide and serotonin in aggressive behavior. Horm. Behav., Vol. 44, No. 3, pp. 233-241

Chipuk, JE. \& Green, DR. (2008). How do BCL-2 proteins induce mitochondrial outer membrane permeabilization? Trends Cell Biol., Vol. 18, pp. 157-164 
Chrousos, GP. (2009). Stress and disorders of the stress system. Nat. Rev. Endocrinol., Vol. 5, No. 7, pp. 374-381

Chuang, DM. (2005). The antiapoptotic actions of mood stabilizers: molecular mechanisms and therapeutic potentials. Ann. N. Y. Acad. Sci., Vol. 1053, pp. 195-204

Citri, A. \& Malenka, RC. (2008). Synaptic plasticity: multiple forms, functions, and mechanisms. Neuropsychopharmacology, Vol. 33, No. 1, pp. 18-41

Clevers, H. (2006). Wnt/ $\beta$-catenin signaling in development and disease. Cell, Vol. 127, pp. $469-480$

Coppen, A. (1967). The biochemistry of affective disorders. Br. J. Psychiatry, Vol. 113, No. 504, pp. 1237-1264

Cowan, KJ. \& Storey, KB. (2003). Mitogen-activated protein kinases: new signaling pathways functioning in cellular responses to environmental stress. J. Exp. Biol., Vol. 206, pp. 1107-1115

Cowen, PJ. (2008). Serotonin and depression: pathophysiological mechanism or marketing myth? Trends Pharmacol. Sci., Vol. 29, No. 9, pp. 433-436

Crisafulli, C., Fabbri, C., Porcelli, S., Drago, A., Spina, E., De Ronchi, D. \& Serretti, A. (2011). Pharmacogenetics of antidepressants. Front. Pharmacol., Vol. 2, Art. 6, pp. 1-21

Delgado, PL., Miller, HL., Salomon, RM., Licinio, J., Krystal, JH., Moreno, FA., Heninger, GR. \& Charney, DS. (1999). Tryptophan-depletion challenge in depressed patients treated with desipramine or fluoxetine: implications for the role of serotonin in the mechanism of antidepressant action. Biol. Psychiatry., Vol. 46, No. 2, pp. 212-220

Derkach, VA., Oh, MC., Guire, ES. \& Soderling, TR. (2007). Regulatory mechanisms of AMPA receptors in synaptic plasticity. Nat. Rev. Neurosci., Vol. 8, No. 2, pp. 101-113

Diazgranados, N., Ibrahim, L., Brutsche, NE., Newberg, A., Kronstein, P., Khalife, S., Kammerer, WA., Quezado, Z., Luckenbaugh, DA., Salvadore, G., Machado-Vieira, R., Manji, HK. \& Zarate, CAJr. (2010). A randomized add-on trial of an N-methylD-aspartate antagonist in treatment-resistant bipolar depression. Arch. Gen. Psychiatry, Vol. 67, No. 8, pp. 793-802

Draganski, B. \& May, A. (2008). Training-induced structural changes in the adult human brain. Behav. Brain Res., Vol. 192, No. 1, pp. 137-142

Drzyzga, ŁR., Marcinowska, A. \& Obuchowicz, E. (2009). Antiapoptotic and neurotrophic effects of antidepressants: a review of clinical and experimental studies. Brain Res. Bull., Vol. 79, No. 5, pp. 248-257

Duman, RS., Heninger, GR. \& Nestler, EJ. (1997). A molecular and cellular theory of depression. Arch. Gen. Psychiatry, Vol. 54, pp. 597-606

Duman, RS. (2002). Synaptic plasticity and mood disorders. Mol. Psychiatry, Vol. 7, pp. S29S34

Duman, RS. \& Monteggia, LM. (2006). A neurotrophic model for stress-related mood disorders. Biol. Psychiatry., Vol. 59, No. 12, pp. 1116-1127

Duman, RS. (2009). Neuronal damage and protection in the pathophysiology and treatment of psychiatric illness: stress and depression. Dialogues Clin. Neurosci., Vol. 11, No. 3, pp. 239-255

Einat, H. \& Manji, HK. (2006). Cellular plasticity cascades: genes-to-behavior pathways in animal models of bipolar disorder. Biol. Psychiatry, Vol. 59, pp. 1160-1171

Eisch, AJ., Bolaños, CA., de Wit, J., Simonak, RD., Pudiak, CM., Barrot, M., Verhaagen, J. \& Nestler, EJ. (2003). Brain-derived neurotrophic factor in the ventral midbrain- 
nucleus accumbens pathway: a role in depression. Biol. Psychiatry., Vol. 54, No. 10, pp. 994-1005

Elkin, I., Shea, MT., Watkins, JT., Imber, SD., Sotsky, SM., Collins, JF., Glass, DR., Pilkonis, PA., Leber, WR., Docherty, JP., Fiester SJ. \& Parloff MB. (1989). National Institute of Mental Health Treatment of Depression Collaborative Research Program. General effectiveness of treatments. Arch. Gen. Psychiatry, Vol. 46, No. 11, pp. 971-982

Etkin, A., Pittenger, C., Polan, HJ. \& Kandel, ER. (2005). Toward a neurobiology of psychotherapy: basic science and clinical applications. J. Neuropsychiatry Clin. Neurosci., Vol. 17, No. 2, pp. 145-158

Fišar, Z. \& Raboch, J. (2008). Depression, antidepressants, and peripheral blood components. Neuroendocrinol. Lett., Vol. 29, pp. 17-28

Fišar, Z. (2009). Phytocannabinoids and endocannabinoids. Curr. Drug Abuse Rev., Vol. 2, No. 1, pp. 51-75

Fišar, Z. \& Hroudová, J. (2010). Intracellular signalling pathways and mood disorders. Folia Biol., Vol. 56, No. 4, pp. 135-148

Fuerer, C., Nusse, R. \& Ten Berge, D. (2008). Wnt signalling in development and disease. EMBO Rep., Vol. 9, pp. 134-138

García-Junco-Clemente, P., Linares-Clemente, P. \& Fernández-Chacón, R. (2005). Active zones for presynaptic plasticity in the brain. Mol. Psychiatry., Vol. 10, No. 2, pp. 185200

Gardner, A. \& Boles, RG. (2011). Beyond the serotonin hypothesis: mitochondria, inflammation and neurodegeneration in major depression and affective spectrum disorders. Prog. Neuropsychopharmacol. Biol. Psychiatry, Vol. 35, No. 3, pp. 730-743

Gass, P. \& Riva, MA. (2007). CREB, neurogenesis and depression. Bioessays, Vol. 29, pp. 957961

Gould, TD., Quiroz, JA., Singh, J., Zarate, CA. \& Manji, HK. (2004). Emerging experimental therapeutics for bipolar disorder: insights from the molecular and cellular actions of current mood stabilizers. Mol. Psychiatry, Vol. 9, No. 8, pp. 734-755

Gould, TD. \& Manji, HK. (2005). Glycogen synthase kinase-3: a putative molecular target for lithium mimetic drugs. Neuropsychopharmacology, Vol. 30, pp. 1223-1237.

Gould, TD., Picchini, AM., Einat, H. \& Manji, HK. (2006). Targeting glycogen synthase kinase-3 in the CNS: implications for the development of new treatments for mood disorders. Curr. Drug Targets, Vol. 7, No. 11, pp. 1399-1409

Gould, TD., Dow, ER., O'Donnell, KC., Chen, G. \& Manji, HK. (2007). Targeting signal transduction pathways in the treatment of mood disorders: recent insights into the relevance of the Wnt pathway. CNS Neurol. Disord. Drug Targets, Vol. 6, No. 3, pp. 193-204

Guo, D., Zhang, JJ. \& Huang, XY. (2010). A new Rac/PAK/GC/cGMP signaling pathway. Mol. Cell. Biochem., Vol. 334, No. 1-2, pp. 99-103

Haddad, JJ., Saadé, NE. \& Safieh-Garabedian, B. (2002). Cytokines and neuro-immuneendocrine interactions: a role for the hypothalamic-pituitary-adrenal revolving axis. J. Neuroimmunol., Vol. 133, No. 1-2, pp. 1-19

Hayden, MS. \& Ghosh S. (2004). Signaling to NF-kappaB. Genes Dev., Vol. 18, pp. 2195-2224

Heninger, GR., Delgado, PL. \& Charney, DS. (1996). The revised monoamine theory of depression: a modulatory role for monoamines, based on new findings from monoamine depletion experiments in humans. Pharmacopsychiatry, Vol. 29, No. 1, pp. 2-11 
Hill, BG., Dranka, BP., Bailey, SM., Lancaster, JRJr. \& Darley-Usmar, VM. (2010). What part of NO don't you understand? Some answers to the cardinal questions in nitric oxide biology. J. Biol. Chem., Vol. 285, No. 26, pp. 19699-19704

Horstink, M., Tolosa, E., Bonuccelli, U., Deuschl, G., Friedman, A., Kanovsky, P., Larsen, JP., Lees, A., Oertel, W., Poewe, W., Rascol, O. \& Sampaio C; European Federation of Neurological Societies; Movement Disorder Society-European Section. (2006). Review of the therapeutic management of Parkinson's disease. Report of a joint task force of the European Federation of Neurological Societies and the Movement Disorder Society-European Section. Part I: early (uncomplicated) Parkinson's disease. Eur. J. Neurol., Vol. 13, pp. 1170-1185

Hroudová, J. \& Fišar, Z. (2011). Connectivity between mitochondrial functions and psychiatric disorders. Psychiat. Clin. Neurosci., Vol. 65, No. 2, pp. 130-141

Jacobs, BL. (2002). Adult brain neurogenesis and depression. Brain Behav. Immun., Vol. 16, pp. 602-609

Janssen, DG., Caniato, RN., Verster, JC. \& Baune, BT. (2010). A psychoneuroimmunological review on cytokines involved in antidepressant treatment response. Hum. Psychopharmacol., Vol. 25, No. 3, pp. 201-215

Jian, K., Chen, M., Cao, X., Zhu, XH., Fung, ML. \& Gao, TM. (2007). Nitric oxide modulation of voltage-gated calcium current by S-nitrosylation and cGMP pathway in cultured rat hippocampal neurons. Biochem. Biophys. Res. Commun., Vol. 359, No. 3, pp. 481-485

Jimerson, DC., Post, RM., Carman, JS., van Kammen, DP., Wood, JH., Goodwin, FK. \& Bunney, WEJr. (1979). CSF calcium: clinical correlates in affective illness and schizophrenia. Biol. Psychiatry, Vol. 14, No 1, pp. 37-51

Joca, SR. \& Guimarães, FS. (2006). Inhibition of neuronal nitric oxide synthase in the rat hippocampus induces antidepressant-like effects. Psychopharmacology (Berl.), Vol. 185, No. 3, pp. 298-305

Johnson, SL. (2005). Life events in bipolar disorder: towards more specific models. Clin. Psychol. Rev., Vol. 25, No. 8, pp. 1008-1027

Joyce, PR. \& Paykel, ES. (1989). Predictors of drug response in depression. Arch. Gen. Psychiatry, Vol. 46, pp. 89-99

Kann, O. \& Kovács, R. (2007). Mitochondria and neuronal activity. Am. J. Physiol. Cell Physiol., Vol. 292, pp. C641-C657

Kasper, S. \& McEwen, BS. (2008). Neurobiological and clinical effects of the antidepressant tianeptine. CNS Drugs, Vol. 22, No. 1, pp. 15-26

Kato, T. \& Kato, N. (2000). Mitochondrial dysfunction in bipolar disorder. Bipolar Disord., Vol. 2, No. 3 Pt 1, pp. 180-190

Kato, T. (2007). Mitochondrial dysfunction as the molecular basis of bipolar disorder: therapeutic implications. CNS Drugs, Vol. 21, No. 1, pp. 1-11

Kato, T. (2008). Role of mitochondrial DNA in calcium signaling abnormality in bipolar disorder. Cell Calcium, Vol. 44, No. 1, pp. 92-102

Kempermann, G. \& Kronenberg, G. (2003). Depressed new neurons?-adult hippocampal neurogenesis and a cellular plasticity hypothesis of major depression. Biol. Psychiatry, Vol. 54, pp. 499-503

Kendler, KS., Karkowski, LM. \& Prescott, CA. (1999). Causal relationship between stressful life events and the onset of major depression. Am. J. Psychiatry, Vol. 156, No. 6, pp. 837-841 
Kim, AH. \& Bonni, A. (2007). Thinking within the D box: initial identification of Cdh1-APC substrates in the nervous system. Mol. Cell. Neurosci., Vol. 34, pp. 281-287

Kim, Y-K., Paik, J-W., Lee, S-W., Yoon, D., Han, C. \& Lee, B-H. (2006). Increased plasma nitric oxide level associated with suicide attempt in depressive patients. Prog. Neuropsychopharmacol. Biol. Psychiatry, Vol. 30, No. 6, pp. 1091-1096

Koo, JW. \& Duman, RS. (2008). IL-1 $\beta$ is an essential mediator of the antineurogenic and anhedonic effects of stress. Proc. Natl. Acad. Sci. USA, Vol. 105, No. 2, pp. 751-756

Kramlinger, KG. \& Post, RM. (1996). Ultra-rapid and ultradian cycling in bipolar affective illness. Br. J. Psychiatry, Vol. 168, No. 3,pp. 314-323

Krishnan, V. \& Nestler, EJ. (2008). The molecular neurobiology of depression. Nature, Vol. 455, No. 7215, pp. 894-902

Kubera, M., Kenis, G., Bosmans, E., Scharpé, S. \& Maes, M. (2000). Effects of serotonin and serotonergic agonists and antagonists on the production of interferon- $\gamma$ and interleukin-10. Neuropsychopharmacology, Vol. 23, No. 1, pp. 89-98

Kuhn, M. (2003). Structure, regulation, and function of mammalian membrane guanylyl cyclase receptors, with a focus on guanylyl cyclase-A. Circ. Res., Vol. 93, pp.700-709

Lee, AL., Ogle, WO. \& Sapolsky, RM. (2002). Stress and depression: possible links to neuron death in the hippocampus. Bipolar Disord., Vol. 4, No. 2, pp. 117-128

Lee, BH., Lee, SW., Yoon, D., Lee, HJ., Yang, JC., Shim, SH., Kim, DH., Ryu, SH., Han, C. \& Kim, YK. (2006). Increased plasma nitric oxide metabolites in suicide attempters. Neuropsychobiology, Vol. 53, No. 3, pp. 127-132

Lee, E., Salic, A., Krüger, R., Heinrich, R. \& Kirschner, MW. (2003). The roles of APC and Axin derived from experimental and theoretical analysis of the Wnt pathway. PLoS Biol., Vol. 1, pp. E10

Leonard, BE. \& Myint, A. (2009). The psychoneuroimmunology of depression. Hum. Psychopharmacol., Vol. 24, No. 3, pp. 165-175

Lie, DC., Colamarino, SA., Song, HJ., Désiré, L., Mira, H., Consiglio, A., Lein, ES., Jessberger, S., Lansford, H., Dearie, AR. \& Gage, FH. (2005). Wnt signalling regulates adult hippocampal neurogenesis. Nature, Vol. 437, pp. 1370-1375

Lipton, P. (1999). Ischemic cell death in brain neurons. Physiol. Rev., Vol. 79, No. 4, pp. 14311568

Liu, X., Rubin, JS. \& Kimmel, AR. (2005). Rapid, Wnt-induced changes in GSK3 $\beta$ associations that regulate $\beta$-catenin stabilization are mediated by Ga proteins. Curr. Biol., Vol. 15, pp. 1989-1997

Maes, M. (2001). The immunoregulatory effects of antidepressants. Hum. Psychopharmacol., Vol. 16, No. 1, pp. 95-103

Maes, M., Yirmyia, R., Noraberg, J., Brene, S., Hibbeln, J., Perini, G., Kubera, M., Bob, P., Lerer, B. \& Maj, M. (2009). The inflammatory \& neurodegenerative (I\&ND) hypothesis of depression: leads for future research and new drug developments in depression. Metab. Brain Dis., Vol. 24, No. 1, pp. 27-53

Mathew, SJ., Manji, HK. \& Charney, DS. (2008). Novel drugs and therapeutic targets for severe mood disorders. Neuropsychopharmacology, Vol, 33, No. 9, pp. 2080-2092

McBain, CJ. \& Kauer, JA. (2009). Presynaptic plasticity: targeted control of inhibitory networks. Curr. Opin. Neurobiol., Vol. 19, No. 3, pp 254-262

McEwen, BS. \& Sapolsky, RM. (1995). Stress and cognitive function. Curr. Opin. Neurobiol., Vol. 5, No. 2, pp. 205-216 
McEwen, BS. (2007). Physiology and neurobiology of stress and adaptation: central role of the brain. Physiol. Rev., Vol. 87, No. 3, pp. 873-904

McEwen, BS., Chattarji, S., Diamond, DM., Jay, TM., Reagan, LP., Svenningsson, P. \& Fuchs, E. (2010). The neurobiological properties of tianeptine (Stablon): from monoamine hypothesis to glutamatergic modulation. Mol. Psychiatry, Vol. 15, No. 3, pp. 237-249

McNamara, RK., Ostrander, M., Abplanalp, W., Richtand, NM., Benoit, SC. \& Clegg, DJ. (2006). Modulation of phosphoinositide-protein kinase C signal transduction by omega-3 fatty acids: implications for the pathophysiology and treatment of recurrent neuropsychiatric illness. Prostaglandins Leukot. Essent. Fatty Acids, Vol. 75, No. 4-5, pp. 237-257

Mendelsohn, D., Riedel, WJ. \& Sambeth, A. (2009). Effects of acute tryptophan depletion on memory, attention and executive functions: a systematic review. Neurosci. Biobehav. Rev., Vol. 33, No. 6, pp. 926-952.

Mendlewicz, J. (2009). Disruption of the circadian timing systems: molecular mechanisms in mood disorders. CNS Drugs, Vol. 23, Suppl 2, pp. 15-26

Mesulam, MM. (1999). Neuroplasticity failure in Alzheimer's disease: bridging the gap between plaques and tangles. Neuron, Vol. 24, No. 3, pp. 521-529

Meyer, JH., Ginovart, N., Boovariwala, A., Sagrati, S., Hussey, D., Garcia, A., Young, T., Praschak-Rieder, N., Wilson, AA. \& Houle, S. (2006). Elevated monoamine oxidase a levels in the brain: an explanation for the monoamine imbalance of major depression. Arch. Gen. Psychiatry, Vol. 63, pp. 1209-1216

Meyer, JH., Wilson, AA., Sagrati, S., Miler, L., Rusjan, P., Bloomfield, PM., Clark, M., Sacher, J., Voineskos, AN. \& Houle S. (2009). Brain monoamine oxidase A binding in major depressive disorder: relationship to selective serotonin reuptake inhibitor treatment, recovery, and recurrence. Arch. Gen. Psychiatry, Vol. 66, No. 12, pp. 1304-1312

Mirnikjoo, B., Brown, SE., Kim, HF., Marangell, LB., Sweatt, JD. \& Weeber, EJ. (2001). Protein kinase inhibition by $\omega-3$ fatty acids. J. Biol. Chem., Vol. 276, No. 14, pp. 10888-10896

Miyamoto, E. (2006). Molecular mechanism of neuronal plasticity: induction and maintenance of long-term potentiation in the hippocampus. J. Pharmacol. Sci., Vol. 100, pp. 433-442

Moghaddam, B. (2002). Stress activation of glutamate neurotransmission in the prefrontal cortex: implications for dopamine-associated psychiatric disorders. Biol. Psychiatry, Vol. 51, No. 10, pp. 775-787

Nelson, JC. (1999). A review of the efficacy of serotonergic and noradrenergic reuptake inhibitors for treatment of major depression. Biol. Psychiatry, Vol. 46, pp. 1301-1308

Nelson, SB. \& Turrigiano, GG. (2008). Strength through diversity. Neuron, Vol. 60, No. 3, pp. 477-482

Nestler, EJ., Barrot, M., DiLeone, RJ., Eisch, AJ., Gold, SJ. \& Monteggia, LM. (2002). Neurobiology of depression. Neuron, Vol. 34, No. 1, pp. 13-25

Nestler, EJ. \& Carlezon, WAJr. (2006). The mesolimbic dopamine reward circuit in depression. Biol. Psychiatry, Vol. 59, No. 12, pp. 1151-1159

Nibuya, M., Nestler, EJ. \& Duman, RS. (1996). Chronic antidepressant administration increases the expression of cAMP response element binding protein (CREB) in rat hippocampus. J. Neurosci., Vol. 16, pp. 2365-2372 
Nikisch, G. (2009). Involvement and role of antidepressant drugs of the hypothalamicpituitary-adrenal axis and glucocorticoid receptor function. Neuro Endocrinol. Lett., Vol. 30, No. 1, pp. 11-16

Nikolaus, S., Antke, C. \& Müller, HW. (2009). In vivo imaging of synaptic function in the central nervous system: II. Mental and affective disorders. Behav. Brain Res., Vol. 204, No. 1, pp. 32-66

Oliet, SHR. \& Mothet, J-P. (2009). Regulation of N-methyl-D-aspartate receptors by astrocytic D-serine. Neuroscience, Vol. 158, No. 1, pp. 275-283

Pace, TW. \& Miller, AH. (2009). Cytokines and glucocorticoid receptor signaling. Relevance to major depression. Ann. N. Y. Acad. Sci., Vol. 1179, pp. 86-105

Papakostas, GI., Thase, ME., Fava, M., Nelson, JC. \& Shelton, RC. (2007). Are antidepressant drugs that combine serotonergic and noradrenergic mechanisms of action more effective than the selective serotonin reuptake inhibitors in treating major depressive disorder? A meta-analysis of studies of newer agents. Biol. Psychiatry, Vol. 62, pp. 1217-1227

Pascale, A., Amadio, M., Govoni, S. \& Battaini, F. (2007). The aging brain, a key target for the future: the protein kinase C involvement. Pharmacol. Res., Vol. 55, pp. 560-569

Paul, IA. \& Skolnick, P. (2003). Glutamate and depression: clinical and preclinical studies. Ann. N. Y. Acad. Sci., Vol. 1003, pp. 250-272

Peineau, S., Bradley, C., Taghibiglou, C., Doherty, A., Bortolotto, ZA., Wang, YT. \& Collingridge, GL. (2008). The role of GSK-3 in synaptic plasticity. Br. J. Pharmacol., Vol. 153, pp. S428-S437

Pittenger, C. \& Duman, RS. (2008). Stress, depression, and neuroplasticity: a convergence of mechanisms. Neuropsychopharmacology, Vol. 33, No. 1, pp. 88-109

Ponti, G., Peretto, P. \& Bonfanti, L. (2008). Genesis of neuronal and glial progenitors in the cerebellar cortex of peripuberal and adult rabbits. PLoS ONE, Vol. 3, No. 6, pp. e2366

Porcelli, S., Drago, A., Fabbri, C. \& Serretti, A. (2011). Mechanisms of antidepressant action: An integrated dopaminergic perspective. Prog. Neuropsychopharmacol. Biol. Psychiatry, Vol. 35, No. 7, pp. 1532-1543

Quiroz, JA., Gray, NA., Kato, T. \& Manji, HK. (2008). Mitochondrially mediated plasticity in the pathophysiology and treatment of bipolar disorder. Neuropsychopharmacology, Vol. 33, No. 11, pp. 2551-2565

Ramsay, RR. \& Gravestock, MB. (2003). Monoamine oxidases: to inhibit or not to inhibit. Mini Rev. Med. Chem., Vol. 3,pp. 129-136

Richelson, E. (1990). Antidepressants and brain neurochemistry. Mayo Clin. Proc., Vol. 65, pp. $1227-1236$

Richelson, E. (2003). Interactions of antidepressants with neurotransmitter transporters and receptors and their clinical relevance. J. Clin. Psychiatry, Vol. 64, Suppl 13, pp. 5-12

Riederer, P., Danielczyk, W. \& Grünblatt, E. (2004). Monoamine oxidase-B inhibition in Alzheimer's disease. NeuroToxicology, Vol. 25, pp. 271-277

Ruhé, HG., Mason, NS. \& Schene, AH. (2007). Mood is indirectly related to serotonin, norepinephrine and dopamine levels in humans: a meta-analysis of monoamine depletion studies. Mol. Psychiatry, Vol. 12, No. 4, pp. 331-359

Sands, WA. \& Palmer, TM. (2008). Regulating gene transcription in response to cyclic AMP elevation. Cell. Signal., Vol. 20, pp. 460-466 
Santarelli, L., Saxe, M., Gross, C., Surget, A., Battaglia, F., Dulawa, S., Weisstaub, N., Lee, J., Duman, R., Arancio, O., Belzung, C. \& Hen, R. (2003). Requirement of hippocampal neurogenesis for the behavioral effects of antidepressants. Science, Vol. 301, pp. 805809

Sapolsky, RM. (1996). Stress, Glucocorticoids, and Damage to the Nervous System: The Current State of Confusion. Stress, Vol. 1, No. 1, pp. 1-19

Sapolsky, RM. (2004). Is impaired neurogenesis relevant to the affective symptoms of depression? Biol. Psychiatry, Vol. 56, No. 3, pp. 137-139

Schildkraut, JJ. (1965). The catecholamine hypothesis of affective disorders: a review of supporting evidence. Am. J. Psychiatry, Vol. 122, No. 5, pp. 509-522

Schroeder, FA., Lin, CL., Crusio, WE. \& Akbarian, S. (2007). Antidepressant-like effects of the histone deacetylase inhibitor, sodium butyrate, in the mouse. Biol. Psychiatry, Vol. 62, No. 1, pp. 55-64

Schulz, P. \& Steimer, T. (2009). Neurobiology of circadian systems. CNS Drugs, Vol. 23, Suppl 2, pp. 3-13

Selvaraj, S., Murthy, NV., Bhagwagar, Z., Bose, SK., Hinz, R., Grasby, PM. \& Cowen, PJ. (2011). Diminished brain 5-HT transporter binding in major depression: a positron emission tomography study with [11C]DASB. Psychopharmacology (Berl.), Vol. 213, No. 2-3, pp. 555-562

Shaltiel, G., Chen, G. \& Manji, HK. (2007). Neurotrophic signaling cascades in the pathophysiology and treatment of bipolar disorder. Curr. Opin. Pharmacol., Vol. 7, pp. 22-26

Silva, AJ., Zhou, Y., Rogerson, T., Shobe, J. \& Balaji, J. (2009). Molecular and cellular approaches to memory allocation in neural circuits. Science, Vol. 326, No. 5951, pp. 391-395

Smith, DF. \& Jakobsen, S. (2009). Molecular tools for assessing human depression by positron emission tomography. Eur. Neuropsychopharmacol., Vol. 19, No. 9, pp. 611-628

Snyder, SH. \& Ferris, CD. (2000). Novel neurotransmitters and their neuropsychiatric relevance. Am. J. Psychiatry, Vol. 157, No. 11, pp. 1738-1751

Soderling, TR. (1999). The Ca-calmodulin-dependent protein kinase cascade. Trends Biochem. Sci., Vol. 24, pp. 232-236

Stahl, SM. \& Felker, A. (2008). Monoamine oxidase inhibitors: a modern guide to an unrequited class of antidepressants. CNS Spectr., Vol. 13, pp. 855-870

Stahl, SM. (2009). Multifunctional drugs: a novel concept for psychopharmacology. CNS Spectr., Vol. 14, No. 2, pp. 71-73

Stork, C. \& Renshaw, PF. (2005). Mitochondrial dysfunction in bipolar disorder: evidence from magnetic resonance spectroscopy research. Mol. Psychiatry, Vol. 10, No. 10, pp. 900-919

Tardito, D., Perez, J., Tiraboschi, E., Musazzi, L., Racagni, G. \&, Popoli, M. (2006). Signaling pathways regulating gene expression, neuroplasticity, and neurotrophic mechanisms in the action of antidepressants: a critical overview. Pharmacol. Rev., Vol. 58, No. 1, pp. 115-134

Taylor, SS., Kim, C., Vigil, D., Haste, NM., Yang, J., Wu, J. \& Anand, GS. (2005). Dynamics of signaling by PKA. Biochim. Biophys. Acta, Vol. 1754, pp. 25-37

Thomas, DD., Ridnour, LA., Isenberg, JS., Flores-Santana, W., Switzer, CH., Donzelli, S., Hussain, P., Vecoli, C., Paolocci, N., Ambs, S., Colton, CA., Harris, CC., Roberts, 
DD. \& Wink, DA. (2008). The chemical biology of nitric oxide: implications in cellular signaling. Free Radic. Biol. Med., Vol. 45, No. 1, pp. 18-31

Tóth, K. \& McBain, CJ. (2000). Target-specific expression of pre- and postsynaptic mechanisms. J. Physiol., Vol. 525.1, pp. 41-51

Tsankova, NM., Berton, O., Renthal, W., Kumar, A., Neve, RL. \& Nestler, EJ. (2006). Sustained hippocampal chromatin regulation in a mouse model of depression and antidepressant action. Nat. Neurosci., Vol. 9, pp. 519-525

Tsankova, N., Renthal, W., Kumar, A. \& Nestler, EJ. (2007). Epigenetic regulation in psychiatric disorders. Nat. Rev. Neurosci., Vol. 8, No. 5, pp. 355-367

Uher, R. (2008). The implications of gene-environment interactions in depression: will cause inform cure? Mol. Psychiatry, Vol. 13, No. 12, pp. 1070-1078

Vetulani, J. \& Sulser, F. (1975). Action of various antidepressant treatments reduces reactivity of noradrenergic cyclic AMP-generating system in limbic forebrain. Nature, Vol. 257, No. 5526, pp. 495-496

Wada, T. \& Penninger, JM. (2004). Mitogen-activated protein kinases in apoptosis regulation. Oncogene, Vol. 23, pp. 2838-2849

Warner-Schmidt, JL. \& Duman, RS. (2006). Hippocampal neurogenesis: opposing effects of stress and antidepressant treatment. Hippocampus, Vol. 16, No. 3, pp. 239-249

Wojda, U., Salinska, E. \& Kuznicki, J. (2008). Calcium ions in neuronal degeneration. IUBMB Life, Vol. 60, No. 9, pp. 575-590

$\mathrm{Wu}, \mathrm{H} .$, Peisley, A., Graef, IA. \& Crabtree, GR. (2007). NFAT signaling and the invention of vertebrates. Trends Cell. Biol., Vol. 17, pp. 251-260

Yasuda, S., Liang, MH., Marinova, Z., Yahyavi, A. \& Chuang, DM. (2009). The mood stabilizers lithium and valproate selectively activate the promoter IV of brainderived neurotrophic factor in neurons. Mol. Psychiatry, Vol. 14, No. 1, pp. 51-59

Yildiz-Yesiloglu, A. \& Ankerst, DP. (2006). Neurochemical alterations of the brain in bipolar disorder and their implications for pathophysiology: a systematic review of the in vivo proton magnetic resonance spectroscopy findings. Prog. Neuropsychopharmacol. Biol. Psychiatry, Vol. 30, No. 6, pp. 969-995

Youdim, MB., Edmondson, D. \& Tipton, KF. (2006). The therapeutic potential of monoamine oxidase inhibitors. Nat. Rev. Neurosci., Vol. 7, pp. 295-309

Zarate, CAJr., Singh, J. \& Manji, HK. (2006a). Cellular plasticity cascades: targets for the development of novel therapeutics for bipolar disorder. Biol. Psychiatry, Vol. 59, No. 11, pp. 1006-1020

Zarate, CAJr., Singh, JB., Carlson, PJ., Brutsche, NE., Ameli, R., Luckenbaugh, DA., Charney, DS. \& Manji, HK. (2006b). A randomized trial of an N-methyl-D-aspartate antagonist in treatment-resistant major depression. Arch. Gen. Psychiatry, Vol. 63, No. 8, pp. 856-864

Zhu, XJ., Hua, Y., Jiang, J., Zhou, QG., Luo, CX., Han, X., Lu, YM. \& Zhu, DY. (2006). Neuronal nitric oxide synthase-derived nitric oxide inhibits neurogenesis in the adult dentate gyrus by down-regulating cyclic AMP response element binding protein phosphorylation. Neuroscience, Vol. 141, No. 2, pp. 827-836 


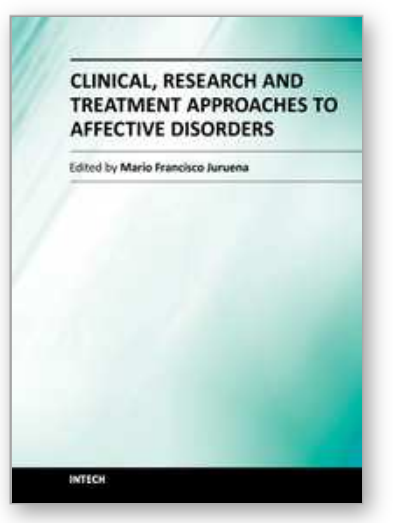

\section{Clinical, Research and Treatment Approaches to Affective Disorders}

Edited by Dr. Mario Juruena

ISBN 978-953-51-0177-2

Hard cover, 364 pages

Publisher InTech

Published online 29, February, 2012

Published in print edition February, 2012

The causes, development and outcomes of disorders are determined by the relationship of psychological, social and cultural factors with biochemistry and physiology. Biochemistry and physiology are not disconnected and different from the rest of our experiences and life events. This system is based on current studies that report that the brain and its cognitive processes show a fantastic synchronization. Written by the foremost experts on Affective Disorders worldwide, this book is characterized by its innovative, refreshing, and highly sensitive perspective on current knowledge of diagnostic, neurobiology, early life stress and treatment of Mood Disorders. The authors share a deep understanding of unique challenges and difficulties involved in Affective Disorders, and have achieved a balance among clinical, research and new treatment approaches to Affective Disorders. The chapters are written in a comprehensive, easily readable, and highly accessible style, stimulating readers, clinicians and researchers.

\section{How to reference}

In order to correctly reference this scholarly work, feel free to copy and paste the following:

Zdeněk Fišar, Jana Hroudová and Jiří Raboch (2012). Neurotransmission in Mood Disorders, Clinical, Research and Treatment Approaches to Affective Disorders, Dr. Mario Juruena (Ed.), ISBN: 978-953-51-01772, InTech, Available from: http://www.intechopen.com/books/clinical-research-and-treatment-approaches-toaffective-disorders/neurotransmission-in-mood-disorders

\section{INTECH}

open science | open minds

\author{
InTech Europe \\ University Campus STeP Ri \\ Slavka Krautzeka 83/A \\ 51000 Rijeka, Croatia \\ Phone: +385 (51) 770447 \\ Fax: +385 (51) 686166 \\ www.intechopen.com
}

\author{
InTech China \\ Unit 405, Office Block, Hotel Equatorial Shanghai \\ No.65, Yan An Road (West), Shanghai, 200040, China \\ 中国上海市延安西路65号上海国际贵都大饭店办公楼 405 单元 \\ Phone: +86-21-62489820 \\ Fax: $+86-21-62489821$
}


(C) 2012 The Author(s). Licensee IntechOpen. This is an open access article distributed under the terms of the Creative Commons Attribution 3.0 License, which permits unrestricted use, distribution, and reproduction in any medium, provided the original work is properly cited. 